\title{
Lck, membrane microdomains, and TCR triggering machinery: defining the new rules of engagement
}

\section{Dominik Filipp*, Ondrej Ballek and Jasper Manning}

Laboratory of Immunobiology, Institute of Molecular Genetics AS CR, Prague, Czech Republic

\section{Edited by:}

Oreste Acuto, University of Oxford, UK

\section{Reviewed by:}

Oreste Acuto, University of Oxford UK

Konstantina Nika, Oxford University, UK

\section{*Correspondence:}

Dominik Filipp, Laboratory of Immunobiology, Institute of Molecular Genetics AS CR, Vídeňská 1083, CZ-142 20 Prague 4, Czech Republic. e-mail: dominik.filipp@img.cas.cz
In spite of a comprehensive understanding of the schematics of T cell receptor (TCR) signaling, the mechanisms regulating compartmentalization of signaling molecules, their transient interactions, and rearrangement of membrane structures initiated upon TCR engagement remain an outstanding problem. These gaps in our knowledge are exemplified by recent data demonstrating that TCR triggering is largely dependent on a preactivated pool of Lck concentrated in T cells in a specific type of membrane microdomains. Our current model posits that in resting $T$ cells all critical components of TCR triggering machinery including TCR/CD3, Lck, Fyn, CD45, PAG, and LAT are associated with distinct types of lipid-based microdomains which represent the smallest structural and functional units of membrane confinement able to negatively control enzymatic activities and substrate availability that is required for the initiation of TCR signaling. In addition, the microdomains based segregation spatially limits the interaction of components of TCR triggering machinery prior to the onset of TCR signaling and allows their rapid communication and signal amplification after TCR engagement, via the process of their coalescence. Microdomains mediated compartmentalization thus represents an essential membrane organizing principle in resting $T$ cells. The integration of these structural and functional aspects of signaling into a unified model of TCR triggering will require a deeper understanding of membrane biology, novel interdisciplinary approaches and the generation of specific reagents. We believe that the fully integrated model of TCR signaling must be based on membrane structural network which provides a proper environment for regulatory processes controlling TCR triggering.

Keywords: Lck, Fyn, membrane microdomains, heavy and light DRMs, TCR triggering, compartmentalization, spatio-temporal regulation

\section{INTRODUCTION}

T cells are prototypical examples of highly sophisticated and meticulously regulated signaling cells. Signaling through the T cell receptor (TCR) has the potential to trigger a broad range of cellular responses. The utility of this potential, on the molecular level, is controlled by the existence of multiple signaling pathways that can be triggered individually or in parallel, in additive or synergistic fashions (Friedl et al., 2005; Acuto et al., 2008; Davis, 2009). However, despite having a comprehensive list of TCR signaling elements and their pathways, there is still a paucity of information concerning very proximal events that initiate $\mathrm{T}$ cell activation. This especially relates to the following questions: (i) how is the engagement of TCR by a peptide ligand presented in the context of MHC (pMHC) transduced across the plasma membrane (PM) to the interior of $\mathrm{T}$ cell and (ii) how is this signal spatially and temporarily coupled to the initiation of receptor's immunoreceptor tyrosinebased activation motif (ITAM) tyrosine phosphorylation itself. In this review, we will give a short account of the past and current literature concerning the mechanism controlling the initiation of enzymatic reactions by two Src-family tyrosine kinases (SFKs), Lck and Fyn, that drive the process of activation in mature peripheral $\mathrm{CD} 4^{+} \mathrm{T}$ cells. We will argue that the tight control of TCR signaling is achieved via a highly regulated process of membrane microdomain-based segregation of various signaling molecules and that this compartmentalization represents the basic organizational principal underpinning the integrity, coordination, and spatio-temporal correlates of TCR proximal signaling.

\section{TCR SIGNALING MODULES}

The functional roadmap of TCR activation is usually presented as a two-dimensional cartoon densely populated by numerous proteins positioned sequentially along the multitude of signaling cascades spanning from the PM to the nucleus. While this simplification is of practical use, recent data suggest the existence of spatially restricted multiprotein modules designed to regulate and perform specific $\mathrm{T}$ cell signaling-related functions. The spatial integration of these modules is usually achieved either by a direct interaction of these proteins or by a common spatial confinement imparting their proximity. Based on their functional and spatiotemporal relationships, Acuto et al. (2008) conveniently grouped the signaling elements in $\mathrm{T}$ cells into three main signaling modules: (i) TCR triggering module (TCR module); (ii) Lck/Fyn regulation module (SFK module); and (iii) signal diversification and regulation module ( $\mathrm{D} / \mathrm{R}$ module).

TCR module is one of the most complex biological signaltransducing systems that contains a highly diversified receptor and 
ligand components (Wucherpfennig et al., 2010). TCR consists of a ligand recognizing variable TCR $\alpha \beta$ heterodimer electrostatically assembled with its signal-transducing chains $\mathrm{CD} 3 \gamma, \mathrm{CD} 3 \delta, \mathrm{CD} 3 \varepsilon$, and $\mathrm{CD} 3 \zeta$ that in their cytoplasmic portion contain 10 ITAMs (Call et al., 2002). This structural complexity of TCR is dictated by the functional requirement for the generation of a biologically relevant signal which is able to translate the affinity of TCR-pMHC interaction, gauged by the duration of their engagement, to quantitatively distinct ITAM phosphorylation patterns (Kersh et al., 1998; Acuto et al., 2008). A critical step in this process is the ordered phosphorylation of ITAMs (Kersh et al., 1998), controlled by SFK module and executed mainly by Lck (van Oers et al., 1996; Hegedus et al., 1999). Phosphorylated ITAMs serve as docking sites for tyrosine kinase ZAP-70 which after being activated by Lck proceeds to phosphorylate the adaptor protein LAT on multiple sites. This in turn, leads to the engagement and assembly of the $\mathrm{D} / \mathrm{R}$ module initiating downstream signaling. Notably, the recruitment of phospholipase $\mathrm{C} \gamma_{1}$, as well as the adaptor proteins Grb2 and GADS to these sites allows the activation of MAPK signaling pathways, $\mathrm{Ca}_{2}^{+}$flux, and formation of multimeric signaling complexes which lead to cytoskeletal reorganization and integrin activation (Nel, 2002; Smith-Garvin et al., 2009). These pathways then converge on both the activation and translocation to the nucleus of critical transcription factors NF-AT, NF- $\mathrm{KB}$, and AP1, which control the expression of the cytokine IL-2, required for activation and proliferation of $\mathrm{T}$ cells in addition to the expression of other activation-inducible genes. Due to the complexity of TCR mediated signaling, a tight regulation of this process is, at least partly, provided by a membrane-based compartmentalization.

\section{LIPID RAFTS, CYTOSKELETON, AND TRANSLOCATIONS}

To achieve unencumbered coordination, specificity, and efficiency in signaling, much of the biochemistry in cell signaling is spatially restricted and timely regulated by the physical segregation of signaling elements into an appropriate confinement. This process of compartmentalization is highly complex and dynamic. It involves not only the engagement of immune receptors, translocation of critical signaling elements to cell-cell contact zones and nucleation of active signaling complexes, but also a cellular architecture that supports it. This includes the lateral segregation of PM into distinct microdomains, called lipid rafts (LR; Horejsi, 2003), and a cytoskeletal network that regulates its structural and dynamic changes (Billadeau et al., 2007; Viola and Gupta, 2007; Burkhardt et al., 2008).

Lipid rafts, also called membrane rafts, are defined as small (5$50 \mathrm{~nm}$ in diameter), heterogeneous, highly dynamic, cholesterol, and sphingolipid-enriched microdomains that compartmentalize cellular processes (Simons and Ikonen, 1997; Simons and Toomre, 2000; Marmor and Julius, 2001; Sharma et al., 2004; Rodgers et al., 2005; Manes and Viola, 2006; Goswami et al., 2008; Lindner and Knorr, 2009; Lingwood and Simons, 2010; Simons and Sampaio, 2011). Due to their stable and highly ordered structure, LR tend to be resistant to solubilization by mild non-ionic detergents and can be isolated as a detergent-resistant membrane (DRM) fraction by discontinued sucrose density gradient centrifugation (SDGC; Edidin, 2003; Lingwood and Simons, 2007). However, this operational definition of LR, originally based solely on their resistance to solubilization and coupled with inconclusive early microscopic investigations into LR organization in living cells, cast serious doubts not only about the content-related fidelity between DRMs and bona-fide native LR, but also challenged the existence of LR in vivo (Munro, 2003; Shaw, 2006; Leslie, 2011). Nowadays, however, using the state-of-art imaging techniques on live cells, the evidence demonstrating lipid and protein-dependent functional subcompartmentalization of cell membrane is being increasingly accepted (reviewed in Lingwood and Simons, 2010; Simons and Sampaio, 2011).

Nevertheless, the question if and to what extent can DRMs be equated to native LR is the subject of ongoing debates. As this review often cites work related to the utility of cell solubilization methods used to obtain various DRMs and the credibility of which is frequently discounted, we feel obliged to provide several remarks justifying the implementation of this experimental approach. While there is a general consensus that DRMs are indeed of an altered composition, it has been demonstrated that a critical factor affecting the degree of their content-related difference is in the type of detergent used (Schuck et al., 2003; Garner et al., 2008). In this context, the widely used Triton X-100 detergent (TX) seems to be a suboptimal choice as it has been shown to induce considerable rearrangement of the original membrane (Koumanov et al., 2005), facilitates the merging of membrane patches of distinct cellular origin (Madore et al., 1999) and scrambles membrane symmetry (Radeva and Sharom, 2004). It has been also documented that TX-derived DRMs represent extraction intermediates in the solubilization of which is a function of time (Lindner and Naim, 2009). In contrast, these adverse effects were not observed for Brij-type detergents such as Brij-96 and 98 (Schuck et al., 2003; Chen et al., 2007). Moreover, the latter type of detergent generates stable (up to several months), content-wise reproducible, small diameter DRMs that selectively retain proteins (Drevot et al., 2002; Chen et al., 2009; Knorr et al., 2009; Otahal et al., 2010; Ballek et al., 2012). As discussed below, another important fact is that Brij solubilization extracts distinct types of DRMs that can be further separated by immunoprecipitation (Drevot et al., 2002; Brugger et al., 2004; Chen et al., 2009; Ballek et al., 2012). While not equating DRMs with native LR, these data suggest that Brijtype DRMs display properties that are compatible with those of native $L R$, at least to the extent that allows us to use them as a biochemical means to probe the heterogeneity of membrane raft environments (Chen et al., 2007, 2009; Lindner and Naim, 2009; Horejsi et al., 2010). It should be noted that DRM partitioning is not only the most frequently used method to assess raft-related transmembrane signaling, but often is instrumental in providing insight into the nature of its components and the underlying mechanism(s) (Lingwood and Simons, 2007).

Given that the solubilization-dependent cofractionation method is the only available biochemical approach to evaluate the protein distribution to DRM, and thus its raft potential, the choice of an appropriate detergent is of critical importance (Lichtenberg et al., 2005; Brown, 2006, 2007; Lingwood and Simons, 2007). In this respect, Brij-type detergents are becoming the tools of choice in characterizing the potential for raftophilicity of signaling molecules before and after initiation of signaling (Horejsi et al., 2010; Quinn, 2010). Thus, the primary importance of the 
solubilization approach is that it can provide the initial insight into the activation-induced changes in DRM association and lay the conceptual network for assessment of the role of lipid-based nanodomains in membrane signaling. However, due to the unavoidable degree of artificiality inherent to this approach, these findings require verification by means of other types of methods. As an example, the correlation between Brij-type DRM cofractionation of CD4 and CD45 molecules and their membrane confinement assessed by using advanced microscopic technologies lent the credibility to the Brij-based solubilization approach (James et al., 2011; Ballek et al., 2012).

Another important aspect of Brij-based membrane solubilization is that at least two distinct fractions of DRMs can be isolated. The first type represents the light DRMs that are easily obtained by SDGC as low density fractions that float to the top of the gradient (Edidin, 2003; Lingwood and Simons, 2007). Recently, a new type of microdomains called high density or heavy DRMs has been documented in immune cell signaling (Rollet-Labelle et al., 2004; Otahal et al., 2010, 2011; Ballek et al., 2012). The light and heavy DRMs share both their resistance and sensitivity to solubilization by a polyoxyethylene type of detergent (such as Brij58 and Brij98) and lauryl maltoside (LM), respectively. On the contrary, due to their different protein-to-lipid ratios, light, and heavy DRMs can be separated from each other by SDGC (Otahal et al., 2010; Ballek et al., 2012). It is of note that Brij58 and Brij98 display a relatively high degree of specificity for a distinct type of LR, thus preserving distinct subpopulations of DRMs (Drevot et al., 2002; Knorr et al., 2009; Lindner and Knorr, 2009). As critical signaling molecules such as pY394Lck, CD3̧, H-ras, CD5, CD28, CD45, LAX associate with heavy DRMs, this non-conventional and so far largely overlooked type of microdomains could represent important membrane structures that are able to support $\mathrm{T}$ cell signaling (Otahal et al., 2010, 2011; Ballek et al., 2012).

Several complementary approaches lend credibility to the notion that LR indeed have a role in the initiation of $\mathrm{T}$ cell signaling. These include but are not limited to (i) functional assays targeting critical signaling molecules to distinct membrane subcompartments (Kabouridis et al., 1997; Zhang et al., 1999; Otahal et al., 2010, 2011); (ii) state of the art electron, fluorescent microscopy, and nanoscopy (reviewed in Lindner and Naim, 2009); (iii) biochemical data suggesting the existence of several distinct types of DRMs extracted from the same cellular membranes (Drevot et al., 2002; Knorr et al., 2009; Ballek et al., 2012); and (iv) requirement for a distinct ganglioside composition of functional LR in $\mathrm{CD}^{+}{ }^{+}$versus $\mathrm{CD} 8^{+} \mathrm{T}$ cells (Nagafuku et al., 2012). The latter study is of significant importance as it shows that activation of $\mathrm{CD}^{+}{ }^{+} \mathrm{T}$ cells, but not their $\mathrm{CD}^{+}$counterparts, isolated from knock-out animals deficient in GM3-derived ganglioside, is severely compromised and animals fail to develop experimental asthma. As GM3 is the main component of LR, these data provide strong in vivo evidence for the functional involvement of LR in T cell signaling (Nagafuku et al., 2012).

TCR/CD3 proximal signaling appears to depend on the integrity of LR (Dykstra et al., 2003). A demonstration that TCR ligation by pMHC complex on antigen-presenting cells (APC) results in both (i) the clustering of LR at the interphase between $\mathrm{T}$ cell and APC, referred to as the immunological synapse (Davis and Dustin, 2004; Chichili et al., 2010), and (ii) the recruitment of CD3 $\zeta$, ZAP-70 kinase, adaptor SLP76, PKC $\theta$, PLC $\gamma_{1}$, Itk, and Carmal kinase to LR, provide strong evidence for the function of LR in T cell signaling (Horejsi, 2003; Filipp and Julius, 2004; Palacios and Weiss, 2004; Kabouridis, 2006; Ballek et al., 2012).

Available data strongly suggest that raft dynamics depends on F-actin rearrangements. According to this model, interactions between actin and actin-binding transmembrane proteins and lipids in the inner leaflet of the PM form a membrane skeletal mesh (MSM) functioning as a structural regulator of LR dynamics (Kusumi et al., 2005). In this respect, several signaling molecules, such as $\mathrm{CD} 3 \zeta, \mathrm{CD} 2, \mathrm{PAG}$, and $\mathrm{CD} 45$, have been shown to be directly or indirectly linked to actin cytoskeleton (Zeyda and Stulnig, 2006). The MSM structure is further supported by its interaction with filamin A (FLNA) which crosslinks actin proteins to generate and sustain the sub-cortical actin cytoskeleton (Tavano et al., 2006). As FLNA also interacts with the co-stimulatory molecule CD28, it has been suggested that TCR-CD28 coaggregation is the principal regulatory mechanism for LR-based compartmentalization of signaling elements at an immunological synapse (Lee et al., 2002; Tavano et al., 2006). Very recent key studies also suggest that actin cytoskeleton plays an indispensible role in the nanoscale organization at the PM of critical T and B cell signaling molecules (Harwood and Batista, 2011; Sherman et al., 2011).

Another important consideration is the time frame of $\mathrm{T}$ cell activation. It has been demonstrated that in resting $\mathrm{T}$ cells the formation of a mature immunological synapse with TCR receptors localized in its central zone called c-SMAC is observed $15-30 \mathrm{~min}$ after the initiation of T cell-APC interaction (Lee et al., 2002). Importantly, this event is preceded by the early recruitment of kinase active Lck to the forming immunological synapse, with maximum activity between 2 and 5 min after the initiation of $\mathrm{T}$ cell-APC conjugation. This pattern was closely followed by the presence of kinase active ZAP-70. Thus, the peak of Lck- and ZAP70-mediated tyrosine kinase signaling initiated upon the TCR engagement occurs well before a mature synapse is fully formed. These data suggest that the initiation of compartmentalization of signaling elements linked to the translocations of critical kinases occurs rapidly after the T cell-APC contact has been established.

\section{SFK MODULE: NON-REDUNDANT ROLE OF Lck AND Fyn IN PROXIMAL TCR SIGNALING}

Whereas all three signaling modules - SFK, TCR, and D/R- contribute to the regulation of threshold, magnitude, and duration of $\mathrm{T}$ cell activation signals, the full understanding of how SFK and TCR modules are integrated is central to the understanding of the initiation of T cell activation. Lck and Fyn provide the critical functions predicating the generation of the most proximal signals emanating from the TCR (Latour and Veillette, 2001). While they share common structural features (Boggon and Eck, 2004; Salmond et al., 2009), mode of regulation (Mayer, 1997), membrane localization (Kabouridis et al., 1997; Resh, 2006), the ability to phosphorylate CD3 $\zeta$ in vitro (Hegedus et al., 1999; Mustelin and Tasken, 2003) and display a partial capacity to compensate for each other's deficiency (Groves et al., 1996), biochemical, genetic, and topographical evidence suggest that their roles in the cellular activation process, while interdependent, are functionally distinct 
(Filipp et al., 2003; Filipp and Julius, 2004). This is in agreement with the fact that Fyn, but not Lck, has been shown to associate with the $\mathrm{CD} 3$ complex via the interaction of its unique domain with $\varepsilon$-chain, although at low stoichiometry (Samelson et al., 1990; Salmond et al., 2011). On the other hand, the delivery of Lck function in TCR proximal signaling is modeled through its stoichiometric interaction with $\mathrm{CD} 4$ which, due to its interaction with the non-variable region of peptide presenting MHCII, relocate Lck to ITAMs of the TCR/CD3 complex (Meuer et al., 1982; Abraham et al., 1991; Maroun and Julius, 1994; Bonnard et al., 1997). While the co-binding of $\mathrm{CD} 4$ to the MHCII ectodomain is not essential for the stability of TCR-pMHC complex (Artyomov et al., 2010), it significantly augments $\mathrm{T}$ cell sensitivity under circumstances when low numbers $(<30)$ of specific peptides are presented (Irvine et al., 2002).

The differential "wiring" mechanism of Lck and Fyn to the TCR/CD3 complex is extended to their capacity to interact with distinct downstream targets and signaling pathways (Zamoyska et al., 2003). Specifically, anti-CD3 stimulation induced tyrosine phosphorylation of the Fyn substrate Cbl but, not the ZAP-70 substrate LAT (Tang et al., 2002). Several studies also demonstrated that Fyn can activate the Ras/Erk pathway in an Lck-independent fashion via the recruitment of Grb2-SOS to hypophosphorylated CD3 $\zeta$ chains (Chau et al., 1998; Chau and Madrenas, 1999; Denny et al., 2000; Methi et al., 2007). In addition, Fyn, via its stimulation through $\mathrm{CD} 3$, has been implicated in the induction of $\mathrm{T}$ cell anergy. This mechanism involves the Fyn-mediated phosphorylation of the LR-associated adaptor protein PAG and the sequestration of active Ras to LR (Davidson et al., 2007; Smida et al., 2007). Consistent with these data, Zamoyska and colleagues, in a series of elegant experiments with inducible expression of Lck or Fyn on their relevant genetically deficient background, demonstrated different effects of Lck and Fyn on T cell development and TCR signaling (Zamoyska et al., 2003; Salmond et al., 2009). The argument for the functional distinction of Lck and Fyn is further supported by the topographical studies demonstrating that LR separates these two kinases. In primary resting $\mathrm{T}$ cells, $75-95 \%$ of Lck resides outside LR while more than $98 \%$ of Fyn is associated with LR (Filipp et al., 2003). Collectively, these data suggest that Fyn plays an important role in the generation of Lck- and ZAP-70- independent signals directly through the CD3 complex. This functional uncoupling of Lck and Fyn signaling is important when building the model of proximal $\mathrm{T}$ cell signaling (see below).

\section{REGULATORY CIRCUITS OPERATING IN SFK MODULE}

Lck displays prototypical structural features of SFKs. It consists of a short N-terminal region post-translationally modified by lipid acylation which is required for its association with the PM. It is followed by unique, $\mathrm{SH} 3$ and $\mathrm{SH} 2$ domains, a short linker region, a catalytic domain and a C-terminal segment (Boggon and Eck, 2004). Its kinase activity is regulated via the reversible phosphorylation of two critical tyrosine residues: (i) positive regulatory Y394 located in the kinase domain and (ii) negative regulatory Y505 in the C-terminal segment (Figure 1). The phosphorylation of Y394, achieved through trans/autophosphorylation, predicates the full kinase activity of Lck and exhibits a dominant effect over the inhibitory Y505 if both tyrosine residues are phosphorylated in tandem (Hardwick and Sefton, 1997; Ashwell and D'Oro, 1999). As Lck provides enzymatic activity which drives the $\mathrm{T}$ cell activation process, the full understanding of mechanisms regulating this activity is essential to build the realistic model of $\mathrm{T}$ cell proximal signaling. Taking advantage of the fact that $\mathrm{T}$ cells are one of the most intensively studied cellular models in respect of the role of membrane subcompartmentalization in signaling, in the context of this review we will highlight those features of SFK regulatory circuits which are connected to raft structures.

The post-translational biochemistry of Y505 is relatively well understood. When phosphorylated (pY505) by C-terminal src kinase (Csk), the C-tail clamps on its own SH2 domain, locking the kinase domain in an inactive, closed conformation (Mayer, 1997). However, since ${ }^{505} \mathrm{pYQPQP}$ is not an optimal sequence for the interaction with the $\mathrm{SH} 2$ domain, it is assumed that the Lck tail would dynamically swing on and off its binding pocket in SH2, making this interaction weak and unstable (Mayer, 1997; Nika et al., 2007). This structural instability is counteracted by the ability of a linker region to interact with its own $\mathrm{SH} 3$ domain and thus maintain the repressed conformation of Lck (Yamaguchi and Hendrickson, 1996; Sicheri et al., 1997; Xu et al., 1997; Rudd et al., 2006; Figure 1). As a consequence, the interaction of SH2 and/or SH3 with their high affinity intracellular ligand can release this inhibitory conformation and positively regulate its kinase activity (Figure 1; Moarefi et al., 1997; Marti et al., 2006).

Csk is a cytosolic protein and its proximity to the PM is a prerequisite for SFK's C-tail tyrosine phosphorylation (Palacios and Weiss, 2004). The recent demonstration that an acute inhibition of Csk activates TCR signaling independently of ligand binding strongly supports the idea that Csk is one of the most critical elements of basal signaling machinery negatively regulating Lck and Fyn activities in resting $\mathrm{T}$ cells (Schoenborn et al., 2011). In mouse thymocytes, approximately $20 \%$ of cytosolic Csk is recruited to the PM via its interaction with PAG (Davidson et al., 2003). PAG is a DRM-associated constitutively tyrosine phosphorylated adaptor which serves as docking sites for various $\mathrm{SH} 2$ domain-containing proteins such as Lck, Fyn, Shc, Vav, GAP, PI3K, ZAP-70, and Syk (Brdicka et al., 2000; Kawabuchi et al., 2000). In resting T cells, the SH2 domain of Csk binds to pY317 of PAG. Because the phosphorylation of this site is attributed to DRM-associated Fyn that, in turn, is negatively regulated by Csk, PAG-Csk complex represents the critical component of a negative homeostatic regulatory feedback mechanism keeping Fyn activity restrained. Importantly, upon TCR engagement, pY371 dephosphorylation releases Csk to the cytosol resulting in a membrane environment conducive to Fyn activation (Brdicka et al., 2000). Interestingly, while one study suggested that CD45 phosphatase can act on pY371 of PAG (Davidson et al., 2003) another failed to confirm this finding (Brdicka et al., 2000).

In the context of membrane compartmentalization, it is not clear how Csk is positioned in the vicinity of most membrane Lck which is not DRM-associated (Filipp et al., 2003). The fact that approximately $50 \%$ of Lck in resting cells is phosphorylated on Y505 (Luo and Sefton, 1990) suggests an alternative way for Csk recruitment to non-DRM fractions. The same notion relates to the recruitment of Csk to DRMs since PAG deficiency has no tangible effect on thymocyte development and proximal $\mathrm{T}$ cell signaling 


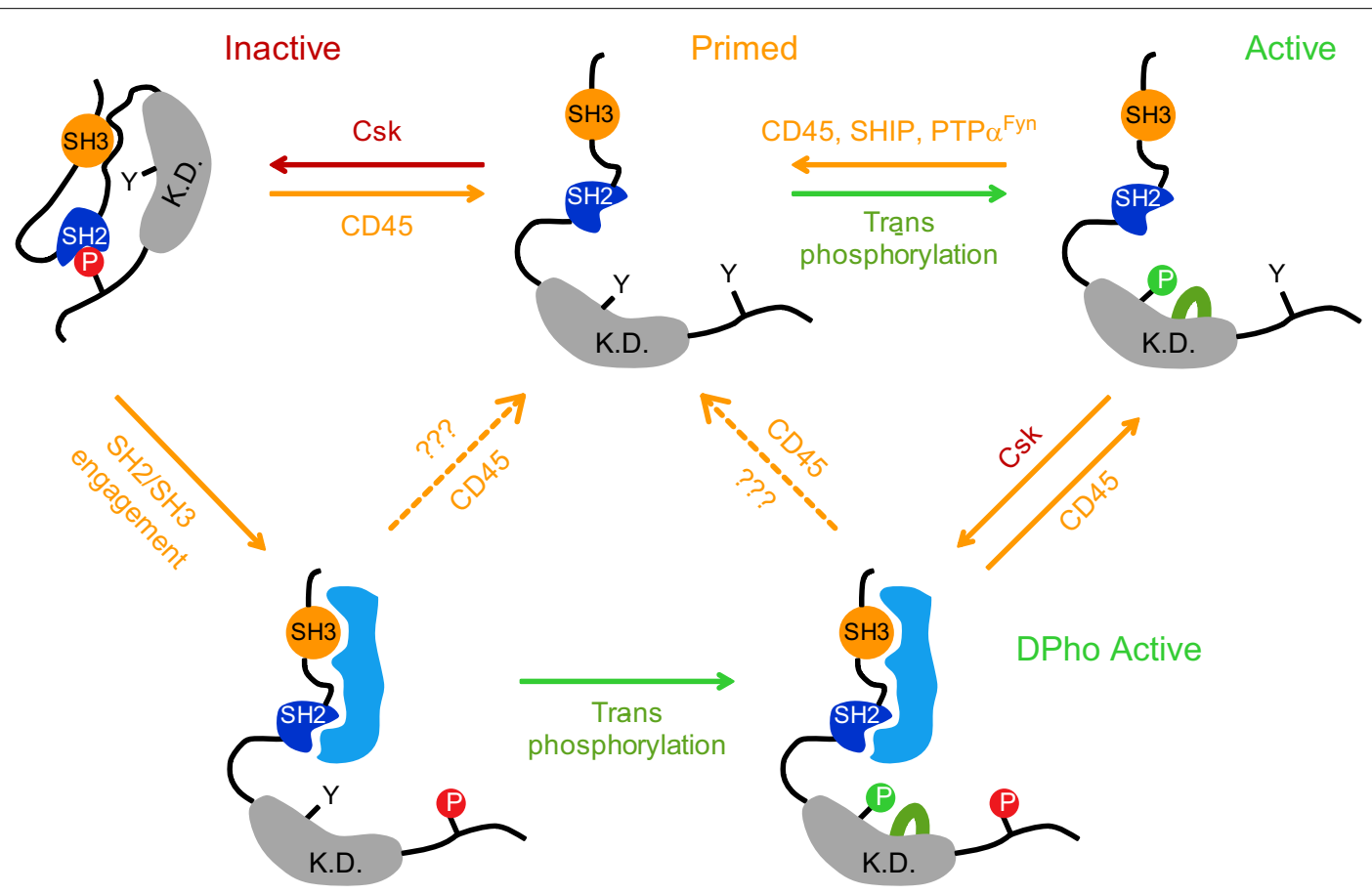

FIGURE 1 | A traditional model postulates that Lck kinase activity is regulated by reversible phosphorylation of two tyrosines residues: positive regulatory tyrosine $\mathrm{Y} 394$ in kinase domain (K.D.) and the negative regulatory tyrosine $\mathbf{Y 5 0 5}$ in the $\mathbf{C}$-terminal end. When Y505 is phosphorylated (depicted here as $\mathrm{P}$ in red circle) by $\mathrm{C}$-terminal src kinase (Csk), it forms an intramolecular bond with its own $\mathrm{SH} 2$ domain, locking the kinase domain in a substrate inaccessible, closed inactive conformation (top left structure). CD45 can dephosphorylate pY505, leaving the Lck structure in an open, primed conformation displaying a relatively low kinase activity (top middle structure). To achieve full kinase activity, the phosphorylation of Y394 (depicted here as $\mathrm{P}$ in green circle) must be achieved through trans/autophosphorylation (top right structure); its dephosphorylation is performed by CD45 or SHIP-1 or alternatively by PTP $\alpha$ in case of Fyn. It has been recently demonstrated that Lck can also persist in a double phosphorylated state (DPho), when both regulatory tyrosines (Y505 and Y394) are phosphorylated concurrently and the kinase retains its activity (bottom structure). DPho state is likely achieved in a two-step process. The first step involves the interaction of high affinity ligand(s) with Lck SH2 and/or SH3 domain which disrupts the closed conformation and is followed by CD4-Lck aggregation-mediated trans/auto phosphorylation of pY394. Alternatively, it is generated by the action of Csk on pY394 Lck. Whether CD45 converts these isoforms to a dephosphorylated, primed conformation or to an active pY394 state in vivo, is unclear (dashed arrows). Red arrows denote negative regulation; green arrows denote positive regulation.
(Veillette et al., 2002; Davidson et al., 2003; Dobenecker et al., 2005). The alternative interaction partners could include DRMresident adapter protein LIME and soluble fraction-associated SIT, paxillin, focal adhesion kinases, and Dok-related adaptors (Veillette et al., 2002; Tedoldi et al., 2006; Yasuda et al., 2007; Schoenborn et al., 2011). Thus, while there is a general consensus that Csk is a critical enzymatic effector of TCR signaling inhibitory mechanism acting on Lck and Fyn, we are still far from a full understanding of the molecular infrastructure supporting its function. From the point of view of TCR triggering, this notion chiefly concerns the process of compartmentalization of those adapter proteins that recruit Csk to the PM as well as the characterization of kinases and phosphatases that regulate this process via acting on tyrosine residues through which Csk is recruited to unidentified adaptors such as Y371 of PAG.

The action of Csk is opposed by a transmembrane phosphatase CD45 which is able to dephosphorylate pY505, leaving the Lck structure in an open, primed conformation with a basal level of kinase activity (D'Oro and Ashwell, 1999; Hermiston et al., 2003; Figure 1). Phosphatase activity is critical for Lck physiology, as CD45 deficiency results in the hyperphosphorylation of
pY505, leading to a dysfunctional Lck and a severely impacted ability to trigger TCR signaling (Stone et al., 1997). This signalingincompetent Lck phenotype can be reverted by the expression of a constitutively active mutant Y505F Lck allele (Seavitt et al., 1999). The positive regulatory role of CD45 contrasts with its enzymatic activities negatively affecting TCR responses. Those include the dephosphorylation of a positive regulatory pY394 residue on Lck and pY-ITAMs on CD3 chains (Trowbridge and Thomas, 1994). Mechanistically, it is unclear how this functional dichotomy of CD45 is coordinated on the molecular level. Attempts to explain it by the mutual interaction of CD45 with a specific extracellular ligand failed to obtain supportive experimental data. It has been reported that within the context of animals, positively (dephosphorylation of pY505) and negatively (dephosphorylation of pY394) directed CD45 activities are predicated by a low to medium and high level of its expression, respectively. Thus, an abundant expression of CD45 can be regarded as a physiologically relevant mechanism to suppress the hyperactivation of $\mathrm{T}$ cells via dephosphorylating pY394 Lck (Mustelin et al., 1989; McNeill et al., 2007). However, the question remains of how opposing activities of CD45 are delivered on a single cellular level, where the 
existence of several pools of Lck with a combinatorial pattern of Y505 and Y394 phosphorylations have been recently demonstrated (Figure 1; Nika et al., 2010).

Available data suggest that membrane compartmentalization plays a critical role in controlling CD45 involvement in regulating Lck activities and TCR signaling. The first evidence for nonhomogenous membrane distribution of CD45 in T cells comes from the observation that the effect of CD45 deficiency on the phosphorylation status of Lck, especially on its negative regulatory tyrosine, is much more pronounced than that on Fyn (Hurley et al., 1993; Stone et al., 1997). That correlates with the significantly reduced kinase activity of membrane associated Lck, but not Fyn in these cells (Biffen et al., 1994). While a possible explanation could relate to sequence differences in the C-terminal tail of Lck and Fyn (Xu et al., 1997) and their ability to interact with CD45 (Nam et al., 2005), it seems that in in vitro conditions CD45 dephosphorylates Lck and Fyn with similar efficiencies (Ostergaard et al., 1989; Mustelin et al., 1992). Thus, the most likely explanation is that the proximity of CD45 with Lck and Fyn is affected by their membrane compartmentalization. Indeed, several groups have reported that only $0-5 \%$ of CD45 was found to be associated with DRMs, while the rest of CD45 pool colocalizes with Lck in a soluble fraction (Edmonds and Ostergaard, 2002; Maksumova et al., 2005; Ballek et al., 2012). It is thus possible that another DRM-associated phosphatase, $\mathrm{PTP} \alpha$, which can dephosphorylate both pY528 and pY417 residues of Fyn, substitutes for CD45 activity (Maksumova et al., 2005; Vacaresse et al., 2008). In addition, the capacity of SHIP-1 phosphatase to target pY394 Lck residue may likely account for the deactivation of kinase active Lck associated with DRMs (Chiang and Sefton, 2001; Kosugi et al., 2001).

Thus, an enzymatic control of the formation and breakage of intramolecular interactions that impact the conformation of Lck and Fyn can be adjusted by a variety of regulatory inputs that harness or activate their kinase activity. TCR-independent regulation of Lck and Fyn through constitutively driven action of Csk and CD45 establishes the net phosphorylation balance at critical tyrosine residues dictating the basal level of their kinase activities. Since in primary resting CD $4^{+}$T cells LR segregate a majority of Lck and Fyn, their regulatory circuits must be coordinated within the limits of redistribution and recruitment of CD45 and Csk, respectively, to these distinct membrane compartments. While our knowledge of these processes is still incomplete, consideration of these parameters should provide a deeper understanding of the constraints on the mechanism controlling TCR triggering.

\section{MODELING THE INVOLVEMENT OF Lck AND Fyn IN TCR TRIGGERING MECHANISM}

Conventionally, Lck in resting non-stimulated T cells is considered to be inactive due to its pY505 status. The binding of the pMHC complex leads to the coaggregation of TCR with CD4, clusteringmediated trans/autophosphorylation of CD4-associated Lck and its juxtaposition to and subsequent phosphorylation of ITAMs of CD3 chains (Mendieta and Gago, 2004; Smith-Garvin et al., 2009). This type of aggregation model of Lck activation relies on regulatory proteins CD45 and Csk that can swiftly and reversibly turn Lck on and off, respectively. A caveat to this model is that during the aggregation period, CD45 would have to dephosphorylate those CD4-associated Lck molecules that accumulated in the vicinity of the TCR-pMHC complex. While the low stoichiometry of interaction between CD45 and CD4-Lck complex has been reported (Bonnard et al., 1997; Irles et al., 2003), the mechanism coupling TCR triggering with CD45-mediated dephosphorylation of pY505 Lck remains elusive.

The main argument discounting this version of the aggregation model is that under some circumstances the CD4 coreceptor is dispensable for TCR signaling (Haughn et al., 1992; Straus and Weiss, 1992; Van Laethem et al., 2007; Acuto et al., 2008). Consistent with this notion, $\mathrm{CD} 4^{-}$but not $\mathrm{CD} 4^{+} \mathrm{T}$ cells responded to $\mathrm{mAb}-$ mediated anti-TCRC $\beta$ stimulation, arguing that the sequestration of Lck by CD4 makes the kinase unavailable for TCR signaling (Haughn et al., 1992). The expression of the mutated form of Lck which was unable to bind to CD4 recapitulated the anti-TCRC $\beta$ responsive phenotype and correlated with the enrichment of Lck in DRMs, concomitant activation of DRM-colocalized Fyn and

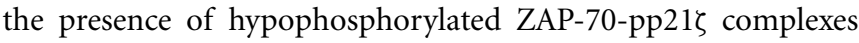
(Haughn et al., 1992, 1998; Filipp et al., 2004). Thus, targeting active Lck locally to the site of TCR engagement via CD4 can provide the much needed sensitivity when signaling a low number of pMHCII $(<30)$, while a less sensitive signaling supported by a "diluted," membrane bound CD4-"free" Lck is driven by a distinct mechanism, likely involving Fyn (Haughn et al., 1992, 1998; Irvine et al., 2002; Filipp et al., 2004).

Lck and Fyn provide critical enzymatic activities that drive TCR triggering (Filipp and Julius, 2004). We, and others, have previously demonstrated that membrane microdomains play an essential role in temporal and spatial coordination of these two kinases (Filipp et al., 2003, 2004; Maksumova et al., 2005). Accordingly, the coaggregation of TCR and CD4 results in the activation of Lck within seconds in soluble fractions followed by its translocation into DRMs and activation of colocalized Fyn. We further showed that only DRM-associated, kinase active Y505F Lck reciprocally co-immunoprecipitates with and activates Fyn. Mutational analyses revealed a profound reduction in the formation of LckFyn complexes and Fyn activation using kinase domain mutants K273R and Y394F of Y505F Lck, both of which have severely compromised kinase activity. Thus, these results suggested a model where Lck-dependent Fyn activation is predicated by proximitymediated transphosphorylation of the Fyn kinase domain in LR (Filipp et al., 2008). It is of note that while the above described studies are consistent with the notion that function of Lck is proximal to that of Fyn when TCR and CD4 are coaggregated, the reciprocal role of Fyn in Lck activation when stimulated via CD3 has also been reported (Sugie et al., 2004).

An unexpected outcome of our study was the characterization of the C-terminal YQPQP sequence acting as a novel cis-acting component essential for the partitioning of Lck to LR (Filipp et al., 2008). Notably, the sequential truncation of YQPQP resulted in an increased reduction of kinase active Lck partitioning to LR, in both fibroblasts and T cells. This, in turn, correlates with ablation of the capacity of these truncates to enhance TCR mediated IL-2 production (Filipp et al., 2008). This is in agreement with our previously published data reporting a requirement for an enrichment of Lck in DRMs for the initiation of proximal TCR $\alpha \beta$ signaling (Filipp 
et al., 2004). Our preliminary data pointed to the existence of multiprotein translocation molecular machinery that is responsible for the targeting of Lck to DRMs via the tethering of its C-terminal sequence directly to microtubular cytoskeletal elements. Indeed, we have already demonstrated that, nocodazole, but not latrunculin B, pharmacological agents inhibiting the polymerization of tubulin and actin, respectively, blocked the TCR/CD4 activationinduced enrichment of Lck in light DRMs (Ballek et al., 2012). These data suggests that the C-terminal sequence of Lck, on the top of its negative regulatory function, targets Lck to microtubular network resulting in the reorganization of cytoskeleton and redistribution of Lck to LR.

\section{A POOL OF PREACTIVATED LCK IN T CELL PROXIMAL SIGNALING}

The exact mechanism regulating the level of kinase activity of Lck prior to stimulation remains obscure. However, precisely quantifying the phosphorylation pattern of Lck in resting $\mathrm{T}$ cells may provide a context from which to base correlations with its main regulators such as CD45 and Csk.

In doing so, recently published data has provided new insight into the source of pY394Lck used for the initiation of TCR signaling (Nika et al., 2010). The authors demonstrated the existence, in primary naïve $\mathrm{CD} 4^{+} \mathrm{T}$ cells, of a substantial pool of preactivated pY394Lck $(\sim 40 \%)$ and showed that this amount remained unchanged on the global cellular level after anti-CD3 as well as antigen mediated TCR stimulation. These findings are consistent with a previous study that was unable to provide evidence of any measurable increase of the structurally open conformation of Lck upon anti-CD3 activation (Paster et al., 2009). Results of these studies invite a discussion concerning the origin, maintenance, and function of the preactivated Lck in spatio-temporal coupling of TCR engagement to the generation of the most proximal biochemical signals (Berry, 2011; Davis and van der Merwe, 2011).

Therefore, with good justification, the search for the mechanism triggering $\mathrm{T}$ cell activation has centered on the organization of membrane structures that support membrane segregation and redistribution of preactivated Lck to the proximity of its physiological substrates. We have recently shown that in resting CD4 ${ }^{+}$ T cells the pool of pY394 Lck is associated with heavy DRM fractions and that $\mathrm{T}$ cell activation led to its redistribution from heavy to light DRMs in a microtubular network-dependent fashion (Ballek et al., 2012). We also found that the kinase active, heavy DRM-associated pool of Lck is membrane confined with CD45 phosphatase. Moreover, most of $\mathrm{CD} 3 \zeta$ was also associated with heavy DRMs.

Importantly, TCR/CD4 aggregation resulted in up to a 50fold increase in the total level of pY394 Lck, whereby the heavy DRM-associated fraction of Lck contributed by $\sim 70 \%$. If we theoretically assume that TCR/CD4 coaggregation activates the entire pool of cellular Lck (this approximation is obviously incorrect as about $10-30 \%$ of Lck is not membrane associated), we estimate that the pool of preactivated pY394 Lck in resting CD4 ${ }^{+} \mathrm{T}$ cells represents only about $\sim 2 \%$ of total kinase (Ballek et al., 2012). However, as the cytosolic pool of Lck which is not involved in TCR signaling is found to be constitutively active (Haughn et al.,
1998), this estimate can be even lower. The reason for this discrepancy with a previously published report is unclear but, likely stems from using various types of T cells, different mode of activation, solubilization protocols, and detection methods (discussed in Ballek et al., 2012). However, in this context, the key observation here is that the lowest levels of pY394 Lck in resting freshly isolated but otherwise unmanipulated primary $\mathrm{CD} 4^{+} \mathrm{T}$ cells were observed when their solubilization was performed instantly in boiled Laemmli buffer. A lysate buffer-mediated cell solubilization reproducibly showed elevated basal levels of pY394. This, in turn, caused a significant diminution of differences in pY394 levels between TCR/CD4 aggregated and non-aggregated samples when Lck was immunoprecipitated (manuscript in preparation).

\section{INCORPORATING MEMBRANE COMPARTMENTALIZATION INTO THE MODEL OF TCR TRIGGERING}

The above described data support Davis and van der Merwe's (2006) kinetic-segregation (KS) model of T cell activation. The model posits that mutual random interactions between Lck, Fyn, tyrosine phosphatases CD45/CD148, and Csk as well as Lck and Fyn themselves, in a resting state, establishes the net balance of Lck and Fyn phosphorylation predicating their kinase activity. According to this model, spontaneous kinase activation is prevented by CD45 phosphatase which is able to dephosphorylate critical regulatory residues pY505 and pY394 on Lck as well as pY-ITAMs on CD3 chains (Trowbridge and Thomas, 1994; Hermiston et al., 2003). Its abundance (two to three molecules of CD45 per TCR complex), high enzymatic activity (100-1000 times faster rate of dephosphorylation compared to the rate of phosphorylation by SFKs), and broad specificity (Trowbridge and Thomas, 1994; Davis and van der Merwe, 2006), make CD45 by far the most efficient suppressor of tyrosine phosphorylation-driven $\mathrm{T}$ cell activation processes (Davis and van der Merwe, 2006; Choudhuri and van der Merwe, 2007).

The presence in T cells of a preactivated pool of Lck has been a welcome addition to the schematics of KS model, as it allows one to ignore the requirement for a specific mechanism which would couple Lck activation to TCR triggering (Chakraborty and Das, 2010; Davis and van der Merwe, 2011). However, our estimation that in resting $\mathrm{T}$ cells less than $2 \%$ of total Lck is kinase active, raises the question of whether this pool is sufficient to provide support for TCR signaling without its prior enlargement (Ballek et al., 2012). A rather low amount of this pool can also significantly impact quantitative aspects of biochemical reactions initiating $\mathrm{T}$ cell activation (Chakraborty and Das, 2010). Moreover, both pY394Lck and a sizeable pool of CD45 were found in heavy DRMs suggesting that kinase activity of pY394Lck is spatially restricted and controlled by its membrane colocalization with this phosphatase (Krotov et al., 2007; Ballek et al., 2012). This observation found its support in a recent demonstration that a fraction of CD45 and CD4 are colocalized by a virtue of membrane confinement accounting for their enormously enhanced association rate (Haugh and Lauffenburger, 1997; James et al., 2011). The significance of this finding is highly relevant to the methodology used for the solubilization of cells as it indicates that Brij58 heavy DRMs selectively concentrate molecules that colocalize to a certain type of membrane environment in vivo. 
The critical TCR signal-generating molecules distribute preferentially to a distinct type of lipid microdomains (Figure 2). Notably, most of CD3 $\zeta$ (and likely the entire TCR/CD3 complex) fractionate to heavy DRMs and display a kinetically synchronized redistribution with active Lck to light DRMs. Whether DRMs with which CD3 $\zeta$ and pY394 Lck are preferentially associated represent a common or slightly distinct type of microdomains is unknown at the present time. Either way, heavy DRMs can support two independent mechanisms inhibiting TCR triggering. First, the membrane colocalization of CD45 with pY394 Lck and/or CD3 $\zeta$ can keep their net tyrosine phosphorylation on a minimal level. Second, as posited by the Safety TCR triggering model, due to its negatively charged lipid composition, these microdomains could provide a suitable environment for the sequestration of intracellular chains of $\mathrm{CD} 3 \zeta$ and $\mathrm{CD} 3 \varepsilon$ via the interaction of its basic residue-rich sequences with the inner leaflet of the PM, thus preventing them from being targeted by active Lck (Kuhns and Davis, 2008; Xu et al., 2008). Despite the fact that the mechanism liberating these CD3 chains from the PM (Fernandes et al., 2010; Gagnon et al., 2010) as well as the lipid composition of heavy DRMs have not been elucidated, coupling the presence of CD45 with the "Safety TCR Trigger" mechanism endows these domains with a powerful anti-pY mechanism to maintain a non-signaling phenotype in resting T cells. Moreover, it is quite likely that adaptor proteins PAG and LAT reside in a slightly distinct type of membrane microdomains, as their profile of Brij58 solubilization pattern is only partially overlapping (Brdicka et al., 2000). LAT in resting $\mathrm{T}$ cells is not tyrosine phosphorylated, suggesting that its resident microdomains are either devoid of tyrosine kinases, or heavily enriched in tyrosine phosphatases. Using two-color photoactivated localization microscopy it has been recently shown that LAT-containing membrane nanoclusters are juxtaposed to and partially overlap with the pool of preassembled complexes of hypophosphorylated CD3 $\zeta$ and ZAP-70 (Haughn et al., 1998; Sherman et al., 2011). Thus, the membrane pool of LAT resides in nanodomains functionally positioned to the vicinity of and efficiently phosphorylated by activated ZAP-70 (Sherman et al., 2011). Alternatively, the activation-dependent recruitment and phosphorylation of LAT from subsynaptic vesicles delivered to these activation zone nanodomains could establish the LAT signaling networks (Williamson et al., 2011). By the same token, light DRMs, preferentially concentrate Fyn with its inhibitory machinery consisting of PAG-Csk complex, $\mathrm{PTP} \alpha$, and likely a small fraction of CD45 (Filipp and Julius, 2004; Ballek et al., 2012). This suggests that while membrane microdomains serve to segregate functionally distinct signaling molecules in resting cells, their juxtaposition allows brisk interaction of their signaling components leading to amplification of the signal upon activation.

An interesting question that arises is how many functionally distinct lipid microdomains are there in the PM of T cells and how do they relate to the generation of the most proximal activation signals? According to the recent study of Horejsi and colleagues who studied the effect of Csk attachment to various types of raft and non-raft membranes it seems that this number is limited (Otahal et al., 2011). Csk targeting to light DRMs using membrane attachment motifs derived from either Lck, Fyn, PAG, or LAT inhibited TCR signaling with a comparable efficiency. Targeting
Csk to heavy DRMs was in this context inefficient. While the mechanism is unclear, what seems to be critical is the enrichment of ITAM-phosphorylated TCR/CD3 complex with kinase active Lck in DRMs. This notion is consistent with the importance of targeting activated Lck to DRMs as it has been demonstrated in previous studies (Filipp et al., 2003, 2004, 2008; Pizzo et al., 2004). This points not only to the structural but possibly also functional distinction between light and heavy DRMs in the context of their roles in the T cell activation process (Figure 2). Heavy DRMs accommodating the signal-inducing Lck and TCR/CD3/ZAP-70 complex are equipped with mechanisms preventing spontaneous activation of TCR signaling. Upon TCR-pMHC interaction and the initiation of signaling, activated Lck and phosphorylated TCR/CD3/ZAP70 complexes coalesce with light DRMs whereby Lck and ZAP-70 engage and activate their prime targets Fyn and LAT, which can further amplify or dampen the signal. Thus, according to this model, light DRMs likely function as a spatially restricted checkpoint regulating the strength and quality of TCR proximal signals. The very recent data with LAT mutants which are unable to target to their natural LR environment provide a strong support for such role of lipid nanodomains in the mechanism of T cell proximal signaling (Otahal et al., 2010; Sherman et al., 2011).

\section{TOWARD THE INTEGRATED MODEL OF TCR SIGNALING: NEW RULES OF ENGAGEMENT}

The models of TCR signaling that detail triggering mechanisms have been described in several previously published papers and reviews. These mechanisms revolves around three basic molecular processes explaining how extracellular TCR engagement is transduced across the PM and translated to a relevant biochemical signal: segregation, conformational change, and aggregation (Werlen and Palmer, 2002; Choudhuri and van der Merwe, 2007; Minguet et al., 2007; Smith-Garvin et al., 2009; Sigalov, 2010). There is compelling evidence that all three processes contribute to TCR triggering, but the mode of their integration is still matter of debate (Choudhuri and van der Merwe, 2007). An integrated model of TCR triggering should accommodate the contribution and spatio-temporal relationships between all participating signaling molecules and membrane structures that guide, coordinate, and support the complex process of $\mathrm{T}$ cell activation. An incorporation of LR to this model has been hampered by insufficient knowledge and controversies related to the quantitative and qualitative parameters of these membrane structures. A major challenge is to provide a mechanism of how TCR engagement invokes its association with LR (Choudhuri and van der Merwe, 2007). Recent data suggest that the TCR receptor in resting cells resides in a special type of microdomains where it colocalizes with a small fraction of pY394 Lck and where upon pMHC-TCR interaction, TCR signaling is initiated (Figure 2; Ballek et al., 2012).

We suggest that the following features of membrane compartmentalization should be considered when building an integrated model of TCR proximal signaling:

- All critical components of TCR signaling triggering machinery including the TCR/CD3 complex, Lck, CD45, Fyn, PAG, and LAT are membrane associated. Sizeable fractions of ZAP-70 and Csk are also recruited to the membrane via their interaction 
A

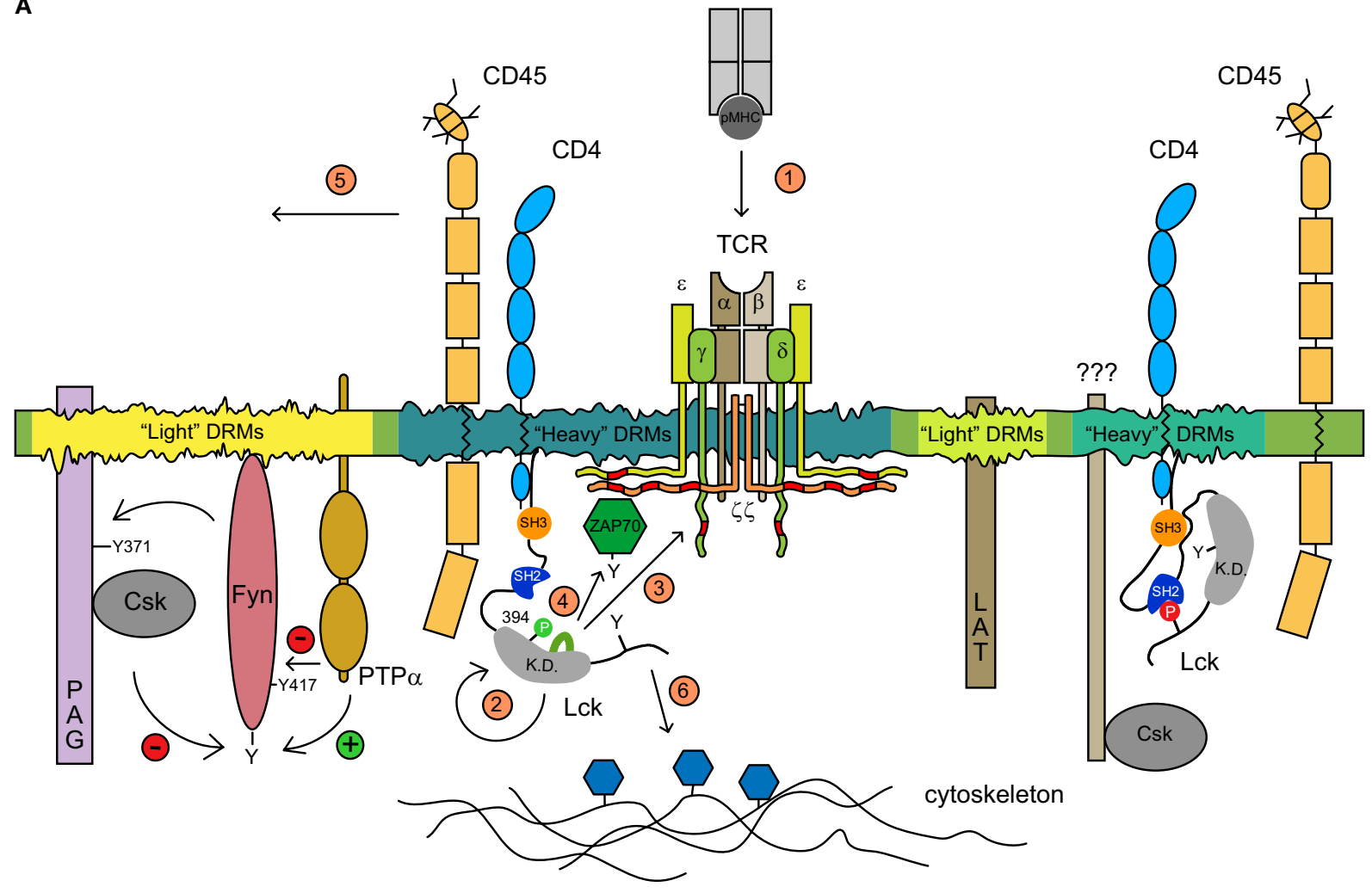

B

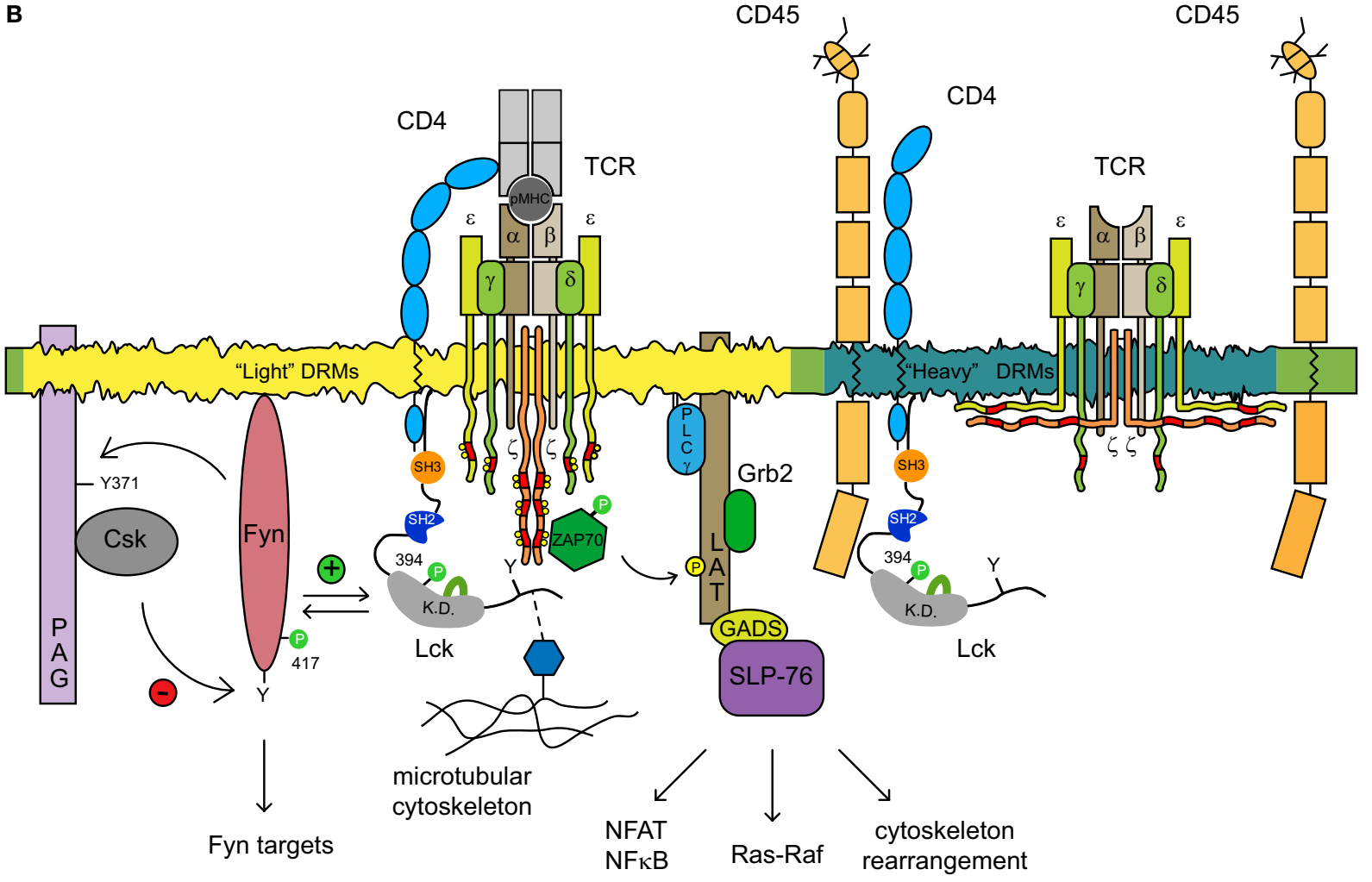

FIGURE 2 | Continued 


\section{FIGURE 2 | Continued}

The proposed model of TCR triggering mechanism. (A) Several types of membrane microdomains segregate distinct pools of functionally related molecules. Two SFK kinases Lck and Fyn reside in different types of microdomains where their kinase activities in resting $T$ cells are controlled via distinct homeostatic mechanisms. The spatial confinement of Fyn within the light DRMs which are conducive to self-phosphorylation is subjected to a negative feedback loop mechanism controlled by PAG-recruited Csk. Kinase active Fyn phosphorylates PAG on Y371 that allows the membrane recruitment of Csk which in turn phosphorylates the negative regulatory Y528 of Fyn, thus dampening its activity. The dephosphorylation of pY528 as well as pY417 Fyn is mediated by either PTP $\alpha$ or by CD45. The pool of pY394 Lck associated with CD4 resides in heavy DRMs, where it colocalizes with TCR/CD3 and CD45. In resting T cells, CD3 $\zeta$ is hypophosphorylated and precomplexed with the inactive ZAP-70 kinase. A distinct pool of heavy DRM-associated kinase inactive CD4-Lck complexes that are largely depleted of CD45 has been also detected. The identity of adaptor proteins able to recruit Csk to Lck is unknown. The adaptor protein LAT likely occupies another type of light DRMs. The activation of T cells is accompanied by a cascade of events depicted in the figure by numbers $1-6$ in orange circles. pMHC-TCR engagement (1) promotes the clustering of CD4-Lck resulting in the activation of Lck (2). In the situation where only a few pMHC complexes are engaged, the preactivated pool of pY394Lck should be sufficient to initiate the signaling cascade; (3) activated Lck proceeds to phosphorylate ITAMs of CD3 chains which are concomitantly released from sequestration by the inner leaflet of PM upon TCR engagement, by a mechanism that has not been elucidated; ZAP-70 kinase recruited to pY-ITAMs is activated by Lck (4); CD45 and other phosphatases that possess a bulky ectodomain are moved laterally from contact zones by a size-exclusion mechanism and likely by virtue of their association with the cytoskeleton which coordinate their membrane redistribution (not depicted; 5); the free C-terminal end of activated Lck is able to interact with elements of the microtubular cytoskeletal network which aid its enrichment in light DRMs likely via the coalescence of heavy and light DRMs (6). (B) The amplification of the TCR signal in light DRMs seems to be critical for the engagement of downstream signaling components. A fraction of TCR/CD3/ZAP-70 active and kinase active pY394 Lck translocates to light DRM and amplifies the signals in two independent ways: (i) colocalization with Fyn disrupts its negative regulatory homeostatic mechanism allowing the proximity-mediated transphosphorylation of the Fyn kinase domain, its activation and subsequent phosphorylation of Fyn targets

Pyk2 and ADAP; and (ii) activated ZAP-70 phosphorylates its main targets LAT and SLP76 adaptors, thus allowing the engagement of downstream targets such as NF-AT, Ras-Raf signaling, and cytoskeleton rearrangement. with pY-ITAMs of CD3 and PAG, respectively. Importantly, all of these signaling molecules are preferentially associated with certain types of lipid-based membrane microdomains.

- Membrane microdomains represent the smallest structural and functional units of membrane confinement of signaling elements that are able to control enzymatic activities supporting the initiation of TCR signaling. This control is imposed by microdomain-localized negative regulatory feedback loops and by biophysical constraints imposed by the properties of lipid-forming membrane structures that control the activities of Lck and Fyn kinases and the phosphorylation of CD3 chains, respectively. Thus, to keep the TCR triggering apparatus on a low signaling potential, TCR/CD3, Lck, and Fyn are regulated separately by inhibitory mechanisms tailored to each of these components via their association with microdomains where these components reside.

- Protein-lipid interactions support the functional infrastructure of microdomains in resting $\mathrm{T}$ cells. Their importance is accentuated by a recent finding that the TCR triggering apparatus and notably the TCR/CD3 complex, CD4-Lck, CD45, and LAT, are composed of monovalent or monomeric proteins. This finding emphasizes the functional contribution of membrane confinement for enhancement of their association rates (James et al., 2011). Once the signaling is triggered and the protein tyrosine phosphorylation drives the formation of the signalosome, protein-protein interactions become predominant (Zeyda and Stulnig, 2006).

- Critical for the generation of Lck-dependent signals is the effect of CD45 on the maintenance of a small pool of pY394 Lck colocalized in a specific type of microdomains. A soluble antibody mediated TCR/CD4 coaggregation resulted in the rapid exclusion of most CD45 from these microdomains suggesting that the membrane apposition formed at the contact zone between APC and T cell is not the sole mechanism accounting for the removal of phosphatases from the vicinity of juxtaposed TCR/CD3-CD4/Lck complexes (Burroughs et al., 2011). The attachment of most if not all microdomain-associated elements of the TCR triggering apparatus to components of microtubular and F-actin-based cytoskeletal network also contributes to the activation-induced redistribution of CD45 and other signaling molecules (Louie et al., 1988; Rozdzial et al., 1998; Ha-Lee et al., 2000; Brdickova et al., 2001; Kwik et al., 2003; Tavano et al., 2004; Cairo et al., 2010).

- The microdomains based spatial segregation of the components of TCR triggering machinery serves in resting $\mathrm{T}$ cells to prevent them from interacting with each other and thus further diminish the probability of spontaneous activation. On the other hand, the juxtaposition of various types of microdomains, as seen for those harboring TCR/CD3 and LAT, allows rapid communication and the signal transfer to downstream components (Sherman et al., 2011). The distribution of Lck and Fyn to distinct types of membrane microdomains provides also the structural resolution for substantiation of Lck-independent Fyn signaling via anti-CD3 stimulation.

\section{CONCLUSION}

Thus, rather than freely diffusing in the membrane, the segregation of the components of TCR triggering machinery into several types of microdomains represent an essential membrane organizing principle in resting $\mathrm{T}$ cells (Figure 2A). These trans-acting structural membrane components spatially limit the availability of signaling molecules prior to the onset of TCR signaling and mediate their communication after engagement, via a process of mutual coalescence. This model is consistent with the suggestion that TCR activation leads to an increased affinity of heavy DRMs to coalesce with light DRMs juxtaposing the pY394Lck/pYCD3 $/$ ZAP-70/complex to the vicinity of the LAT adaptor protein (Otahal et al., 2010; Kennedy et al., 2011; Sherman et al., 2011), allowing thus the amplification of the activation signal. A complementary model of membrane compartmentalization called "fences and pickets," that is based on the presence of physical barriers formed by transmembrane proteins attached to the submembrane cytoskeletal network has been 
recently described (Kusumi et al., 2005). While this model can explain the significantly retarded coefficient of membrane diffusion of signaling molecules and lipids in resting $\mathrm{T}$ cells as well as their rapid immobilization upon initiation of TCR signaling, the microdomain model provides the resolution for the physiological regulation of the "ground state" of the TCR signaling apparatus. The integration of structural and functional aspects of microdomain and "fences and pickets" models with various aspects of distinct mechanisms underpinning TCR triggering will require a deeper understanding of membrane biology, novel interdisciplinary approaches and the generation of specific reagents. We believe that major advances in this exciting and rapidly progressing field of $\mathrm{T}$ cell biology can be achieved only when regulatory processes controlling TCR triggering will be considered in the context of the membrane structures that support them.

It has been 20 years since the publication of the seminal paper by Brown and Rose (1992) which opened up a world

\section{REFERENCES}

Abraham, N., Miceli, M. C., Parnes, J. R., and Veillette, A. (1991). Enhancement of $\mathrm{T}$-cell responsiveness by the lymphocyte-specific tyrosine protein kinase p56lck. Nature 350, $62-66$.

Acuto, O., di Bartolo, V., and Micheli, F. (2008). Tailoring T-cell receptor signals by proximal negative feedback mechanisms. Nat. Rev. Immunol. 8 , 699-712.

Artyomov, M. N., Lis, M., Devadas, S., Davis, M. M., and Chakraborty, A. K. (2010). CD4 and CD8 binding to MHC molecules primarily acts to enhance Lck delivery. Proc. Natl. Acad. Sci. U.S.A. 107, 16916-16921.

Ashwell, J. D., and D'Oro, U. (1999). CD45 and Src-family kinases: and now for something completely different. Immunol. Today 20, 412-416.

Ballek, O., Brouckova, A., Manning, J., and Filipp, D. (2012). A specific type of membrane microdomains is involved in the maintenance and translocation of kinase active Lck to lipid rafts. Immunol. Lett. doi:10.1016/j.imlet.2012.01.001

Berry, R. (2011). The role of $\mathrm{L}(\mathrm{u}) \mathrm{ck}$ in T cell triggering. Sci. Signal. $4, \mathrm{jc} 2$.

Biffen, M., McMichael-Phillips, D., Larson, T., Venkitaraman, A., and Alexander, D. (1994). The CD45 tyrosine phosphatase regulates specific pools of antigen receptor-associated p59fyn and CD4-associated p56lck tyrosine in human T-cells. $E M B O \mathrm{~J} .13$, 1920-1929.

Billadeau, D. D., Nolz, J. C., and Gomez, T. S. (2007). Regulation of T-cell activation by the cytoskeleton. Nat. Rev. Immunol. 7, 131-143.
Boggon, T. J., and Eck, M. J. (2004). Structure and regulation of Src family kinases. Oncogene 23, 7918-7927.

Bonnard, M., Maroun, C. R., and Julius, M. (1997). Physical association of CD4 and CD45 in primary, resting CD4+ T cells. Cell. Immunol. 175, 1-11.

Brdicka, T., Pavlistova, D., Leo, A., Bruyns, E., Korinek, V., Angelisova, P., Scherer, J., Shevchenko, A., Hilgert, I., Cerny, J., Drbal, K., Kuramitsu, Y., Kornacker, B., Horejsi, V., and Schraven, B. (2000). Phosphoprotein associated with glycosphingolipid-enriched microdomains (PAG), a novel ubiquitously expressed transmembrane adaptor protein, binds the protein tyrosine kinase csk and is involved in regulation of $\mathrm{T}$ cell activation. $J$. Exp. Med. 191, 1591-1604.

Brdickova, N., Brdicka, T., Andera, L., Spicka, J., Angelisova, P., Milgram, action between two adapter proteins, PAG and EBP50: a possible link between membrane rafts and actin cytoskeleton. FEBS Lett. 507, 133-136.

Brown, D. A. (2006). Lipid rafts, detergent-resistant membranes, and raft targeting signals. Physiology (Bethesda) 21, 430-439.

Brown, D. A. (2007). Analysis of raft affinity of membrane proteins by detergent-insolubility. Methods Mol. Biol. 398, 9-20.

Brown, D. A., and Rose, J. K. (1992). Sorting of GPI-anchored proteins to glycolipid-enriched membrane subdomains during transport to the apical cell surface. Cell 68, 533-544.

Brugger, B., Graham, C., Leibrecht, I., Mombelli, E., Jen, A., Wieland, S. L., and Horejsi, V. (2001). Inter-

of studies on the role of lipids rafts in membrane bioactivities and significantly enhanced our knowledge of membrane signaling. Hence, we would like to convey our conviction that the biochemical approach still provides a valuable tool to assess the validity of protein potential for membrane rafts. The careful interpretation of experimental data allows the construction of a hypothetical model that can be further scrutinized by the state-of-art imaging and biophysical techniques. These techniques in combination with the solubilization method would produce many new exciting discoveries in the years to come.

\section{ACKNOWLEDGMENTS}

This work was supported by Grant 310/09/2084 and Grant P302/12/G101 from Grant Agency of Czech Republic (GA CR) and Grant AVOZ50520514 from the Academy of Sciences of the Czech Republic. We thank V. Horejší for critical reading of the manuscript.

F., and Morris, R. (2004). The membrane domains occupied by glycosylphosphatidylinositolanchored prion protein and Thy-1 differ in lipid composition. J. Biol. Chem. 279, 7530-7536.

Burkhardt, J. K., Carrizosa, E., and Shaffer, M. H. (2008). The actin cytoskeleton in $\mathrm{T}$ cell activation. Annu. Rev. Immunol. 26, 233-259.

Burroughs, N. J., Kohler, K., Miloserdov, V., Dustin, M. L., van der Merwe, P. A., and Davis, D. M. (2011). Boltzmann energy-based image analysis demonstrates that extracellular domain size differences explain protein segregation at immune synapses. PLoS Comput. Biol. 7, e1002076. doi:10.1371/journal.pcbi.1002076

Cairo, C. W., Das, R., Albohy, A., Baca, Q. J., Pradhan, D., Morrow, J. S., Coombs, D., and Golan, D. E. (2010). Dynamic regulation of CD45 lateral mobility by the spectrin-ankyrin cytoskeleton of T cells. J. Biol. Chem. 285, 11392-11401.

Call, M. E., Pyrdol, J., Wiedmann, M., and Wucherpfennig, K. W. (2002). The organizing principle in the formation of the $\mathrm{T}$ cell receptor-CD3 complex. Cell 111, 967-979.

Chakraborty, A. K., and Das, J. (2010). Pairing computation with experimentation: a powerful coupling for understanding T cell signalling. Nat. Rev. Immunol. 10, 59-71.

Chau, L. A., Bluestone, J. A., and Madrenas, J. (1998). Dissociation of intracellular signaling pathways in response to partial agonist ligands of the T cell receptor. J. Exp. Med. 187, 1699-1709.

Chau, L. A., and Madrenas, J. (1999). Phospho-LAT-independent activation of the ras-mitogenactivated protein kinase pathway: a differential recruitment model of TCR partial agonist signaling. J. Immunol. 163, 1853-1858.

Chen, X., Jen, A., Warley, A., Lawrence, M. J., Quinn, P. J., and Morris, R. J. (2009). Isolation at physiological temperature of detergentresistant membranes with properties expected of lipid rafts: the influence of buffer composition. Biochem. J. 417, 525-533.

Chen, X., Morris, R., Lawrence, M. J., and Quinn, P. J. (2007). The isolation and structure of membrane lipid rafts from rat brain. Biochimie 89, 192-196.

Chiang, G. G., and Sefton, B. M. (2001). Specific dephosphorylation of the Lck tyrosine protein kinase at Tyr394 by the SHP-1 protein-tyrosine phosphatase. J. Biol. Chem. 276, 23173-23178.

Chichili, G. R., Westmuckett, A. D., and Rodgers, W. (2010). T cell signal regulation by the actin cytoskeleton. $J$. Biol. Chem. 285, 14737-14746.

Choudhuri, K., and van der Merwe, P. A. (2007). Molecular mechanisms involved in $\mathrm{T}$ cell receptor triggering. Semin. Immunol. 19, 255-261.

Davidson, D., Bakinowski, M., Thomas, M. L., Horejsi, V., and Veillette, A. (2003). Phosphorylation-dependent regulation of $\mathrm{T}$-cell activation by PAG/Cbp, a lipid raft-associated transmembrane adaptor. Mol. Cell. Biol. 23, 2017-2028.

Davidson, D., Schraven, B., and Veillette, A. (2007). PAG-associated FynT regulates calcium signaling and promotes anergy in Tlymphocytes. Mol. Cell. Biol. 27, 1960-1973. 
Davis, D. M. (2009). Mechanisms and functions for the duration of intercellular contacts made by lymphocytes. Nat. Rev. Immunol. 9, 543-555.

Davis, D. M., and Dustin, M. L. (2004). What is the importance of the immunological synapse? Trends Immunol. 25, 323-327.

Davis, S. J., and van der Merwe, P. A. (2006). The kinetic-segregation model: TCR triggering and beyond. Nat. Immunol. 7, 803-809.

Davis, S. J., and van der Merwe, P. A. (2011). Lck and the nature of the $\mathrm{T}$ cell receptor trigger. Trends Immunol. 32, 1-5.

Denny, M. F., Patai, B., and Straus, D. B. (2000). Differential T-cell antigen receptor signaling mediated by the Src family kinases Lck and Fyn. Mol. Cell. Biol. 20, 1426-1435.

Dobenecker, M. W., Schmedt, C., Okada, M., and Tarakhovsky, A. (2005). The ubiquitously expressed Csk adaptor protein Cbp is dispensable for embryogenesis and Tcell development and function. Mol. Cell. Biol. 25, 10533-10542.

D'Oro, U., and Ashwell, J. D. (1999). Cutting edge: the CD45 tyrosine phosphatase is an inhibitor of Lck activity in thymocytes. J. Immunol. 162, 1879-1883.

Drevot, P., Langlet, C., Guo, X. J., Bernard, A. M., Colard, O., Chauvin, J. P., Lasserre, R., and $\mathrm{He}$, H. T. (2002). TCR signal initiation machinery is pre-assembled and activated in a subset of membrane rafts. EMBO J. 21, 1899-1908.

Dykstra, M., Cherukuri, A., Sohn, H. W., Tzeng, S. J., and Pierce, S. K. (2003). Location is everything: lipid rafts and immune cell signaling. Annu. Rev. Immunol. 21, 457-481.

Edidin, M. (2003). The state of lipid rafts: from model membranes to cells. Annu. Rev. Biophys. Biomol. Struct. 32, 257-283.

Edmonds, S. D., and Ostergaard, H. L. (2002). Dynamic association of CD45 with detergent-insoluble microdomains in T lymphocytes. $J$. Immunol. 169, 5036-5042.

Fernandes, R. A., Yu, C., Carmo, A. M., Evans, E. J., van der Merwe, P. A., and Davis, S. J. (2010). What controls T cell receptor phosphorylation? Cell 142, 668-669.

Filipp, D., and Julius, M. (2004). Lipid rafts: resolution of the "fyn problem?” Mol. Immunol. 41, 645-656.

Filipp, D., Leung, B. L., Zhang, J., Veillette, A., and Julius, M. (2004). Enrichment of lck in lipid rafts regulates colocalized fyn activation and the initiation of proximal signals through TCR alpha beta. J. Immunol. 172, 4266-4274.

Filipp, D., Moemeni, B., Ferzoco, A., Kathirkamathamby, K., Zhang, J., Ballek, O., Davidson, D., Veillette, A., and Julius, M. (2008). Lckdependent Fyn activation requires $\mathrm{C}$ terminus-dependent targeting of kinase-active Lck to lipid rafts. J. Biol. Chem. 283, 26409-26422.

Filipp, D., Zhang, J., Leung, B. L., Shaw, A., Levin, S. D., Veillette, A., and Julius, M. (2003). Regulation of Fyn through translocation of activated Lck into lipid rafts. J. Exp. Med. 197, 1221-1227.

Friedl, P., den Boer, A. T., and Gunzer, M. (2005). Tuning immune responses: diversity and adaptation of the immunological synapse. Nat. Rev. Immunol. 5, 532-545.

Gagnon, E., Xu, C., Yang, W., Chu, H. H., Call, M. E., Chou, J. J., and Wucherpfennig, K. W. (2010). Response multilayered control of $\mathrm{T}$ cell receptor phosphorylation. Cell 142, 669-671.

Garner, A. E., Smith, D. A., and Hooper, N. M. (2008). Visualization of detergent solubilization of membranes: implications for the isolation of rafts. Biophys. J. 94, 1326-1340.

Goswami, D., Gowrishankar, K., Bilgrami, S., Ghosh, S., Raghupathy, R., Chadda, R., Vishwakarma, R., Rao, M., and Mayor, S. (2008). Nanoclusters of GPI-anchored proteins are formed by cortical actin-driven activity. Cell 135, 1085-1097.

Groves, T., Smiley, P., Cooke, M. P., Forbush, K., Perlmutter, R. M., and Guidos, C. J. (1996). Fyn can partially substitute for Lck in T Lymphocyte development. Immunity 5, 417-428.

Ha-Lee, Y. M., Lee, Y., Kim, Y. K., and Sohn, J. (2000). Cross-linking of CD4 induces cytoskeletal association of CD4 and p56lck. Exp. Mol. Med. $32,18-22$.

Hardwick, J. S., and Sefton, B. M. (1997). The activated form of the Lck tyrosine protein kinase in cells exposed to hydrogen peroxide is phosphorylated at both Tyr-394 and Tyr-505. J. Biol. Chem. 272, 25429-25432.

Harwood, N. E., and Batista, F. D. (2011). The cytoskeleton coordinates the early events of B-cell activation. Cold Spring Harb. Perspect. Biol. 3, a002360.

Haugh, J. M., and Lauffenburger, D. A. (1997). Physical modulation of intracellular signaling processes by locational regulation. Biophys. J. 72, 2014-2031.

Haughn, L., Gratton, S., Caron, L., Sekaly, R. P., Veillette, A., and Julius, M. (1992). Association of tyrosine kinase p56lck with CD4 inhibits the induction of growth through the alpha beta T-cell receptor. Nature 358, 328-331.

Haughn, L., Leung, B., Boise, L., Veillette, A., Thompson, C., and Julius, M. (1998). Interleukin 2mediated uncoupling of $\mathrm{T}$ cell receptor alpha/beta from CD3 signaling. $J$. Exp. Med. 188, 1575-1586.

Hegedus, Z., Chitu, V., Toth, G. K. Finta, C., Varadi, G., Ando, I., and Monostori, E. (1999). Contribution of kinases and the CD45 phosphatase to the generation of tyrosine phosphorylation patterns in the T-cell receptor complex zeta chain. Immunol. Lett. 67, 31-39.

Hermiston, M. L., Xu, Z., and Weiss, A. (2003). CD45: a critical regulator of signaling thresholds in immune cells. Annu. Rev. Immunol. 21, 107-137.

Horejsi, V. (2003). The roles of membrane microdomains (rafts) in $\mathrm{T}$ cell activation. Immunol. Rev. 191, 148-164.

Horejsi, V., Otahal, P., and Brdicka, T. (2010). LAT - an important raftassociated transmembrane adaptor protein. Delivered on 6 July 2009 at the 34th FEBS Congress in Prague, Czech Republic. FEBS J. 277, 4383-4397.

Hurley, T. R., Hyman, R., and Sefton, B. M. (1993). Differential effects of expression of the CD45 tyrosine protein phosphatase on the tyrosine phosphorylation of the lck, fyn, and c-src tyrosine protein kinases. $\mathrm{Mol}$. Cell. Biol. 13, 1651-1656.

Irles, C., Symons, A., Michel, F., Bakker T. R., van der Merwe, P. A., and Acuto, O. (2003). CD45 ectodomain controls interaction with GEMs and Lck activity for optimal TCR signaling. Nat. Immunol. 4, 189-197.

Irvine, D. J., Purbhoo, M. A., Krogsgaard, M., and Davis, M. M. (2002). Direct observation of ligand recognition by $\mathrm{T}$ cells. Nature 419, 845-849.

James, J. R., McColl, J., Oliveira, M. I., Dunne, P. D., Huang, E., Jansson, A., Nilsson, P., Sleep, D. L., Goncalves, C. M., Morgan, S. H., Felce, J. H., Mahen, R., Fernandes, R. A., Carmo, A. M., Klenerman, D., and Davis, S. J. (2011). The T cell receptor triggering apparatus is composed of monovalent or monomeric proteins. J. Biol. Chem. 286, 31993-32001.

Kabouridis, P. S. (2006). Lipid rafts in T cell receptor signalling. Mol. Membr. Biol. 23, 49-57.

Kabouridis, P. S., Magee, A. I., and Ley, S. C. (1997). S-acylation of LCK protein tyrosine kinase is essential for its signalling function in T lymphocytes. EMBO J. 16, 4983-4998.

Kawabuchi, M., Satomi, Y., Takao, T., Shimonishi, Y., Nada, S., Nagai, K., Tarakhovsky, A., and Okada, M. (2000). Transmembrane phosphoprotein Cbp regulates the activities of Src-family tyrosine kinases. Nature 404, 999-1003.

Kennedy, C., Nelson, M. D., and Bamezai, A. K. (2011). Analysis of detergent-free lipid rafts isolated from a CD4+ T cell line: Interaction with antigen presenting cells promotes coalescing of lipid rafts. Cell Commun. Signal. 9, 31.

Kersh, E. N., Shaw, A. S., and Allen, P. M. (1998). Fidelity of T cell activation through multistep $\mathrm{T}$ cell receptor zeta phosphorylation. Science 281, 572-575.

Knorr, R., Karacsonyi, C., and Lindner, R. (2009). Endocytosis of MHC molecules by distinct membrane rafts. $J$. Cell. Sci. 122, 1584-1594.

Kosugi, A., Sakakura, J., Yasuda, K., Ogata, M., and Hamaoka, T. (2001). Involvement of SHP-1 tyrosine phosphatase in TCR-mediated signaling pathways in lipid rafts. Immunity 14, 669-680.

Koumanov, K. S., Tessier, C., Momchilova, A. B., Rainteau, D., Wolf, C., and Quinn, P. J. (2005). Comparative lipid analysis and structure of detergent-resistant membrane raft fractions isolated from human and ruminant erythrocytes. Arch. Biochem. Biophys. 434, 150-158.

Krotov, G. I., Krutikova, M. P., Zgoda, V. G., and Filatov, A. V. (2007). Profiling of the CD4 receptor complex proteins. Biochemistry Mosc. 72, 1216-1224.

Kuhns, M. S., and Davis, M. M. (2008). The safety on the TCR trigger. Cell 135, 594-596.

Kusumi, A., Ike, H., Nakada, C., Murase, K., and Fujiwara, T. (2005). Single-molecule tracking of membrane molecules: plasma membrane compartmentalization and dynamic assembly of raft-philic signaling molecules. Semin. Immunol. 17, 3-21.

Kwik, J., Boyle, S., Fooksman, D., Margolis, L., Sheetz, M. P., and Edidin, M. (2003). Membrane cholesterol, lateral mobility, and the phosphatidylinositol 4,5-bisphosphate-dependent organization of cell actin. Proc. Natl. Acad. Sci. U.S.A. 100, 13964-13969.

Latour, S., and Veillette, A. (2001). Proximal protein tyrosine kinases in immunoreceptor signaling. Curr. Opin. Immunol. 13, 299-306.

Lee, K. H., Holdorf, A. D., Dustin, M. L., Chan, A. C., Allen, P. M., and Shaw, 
A. S. (2002). T cell receptor signaling precedes immunological synapse formation. Science 295, 1539-1542.

Leslie, M. (2011). Do lipid rafts exist? Science 334, 1046-1047.

Lichtenberg, D., Goni, F. M., and Heerklotz, H. (2005). Detergent-resistant membranes should not be identified with membrane rafts. Trends Biochem. Sci. 30, 430-436.

Lindner, R., and Knorr, R. (2009). Rafting trips into the cell. Commun. Integr. Biol. 2, 420-421.

Lindner, R., and Naim, H. Y. (2009). Domains in biological membranes. Exp. Cell Res. 315, 2871-2878.

Lingwood, D., and Simons, K. (2007). Detergent resistance as a tool in membrane research. Nat. Protoc. 2, 2159-2165.

Lingwood, D., and Simons, K. (2010). Lipid rafts as a membraneorganizing principle. Science 327, 46-50.

Louie, R. R., King, C. S., MacAuley, A., Marth, J. D., Perlmutter, R. M., Eckhart, W., and Cooper, J. A. (1988). p56lck protein-tyrosine kinase is cytoskeletal and does not bind to polyomavirus middle $\mathrm{T}$ antigen. $J$. Virol. 62, 4673-4679.

Luo, K. X., and Sefton, B. M. (1990). Analysis of the sites in p56lck whose phosphorylation is induced by tetradecanoyl phorbol acetate. Oncogene 5, 803-808.

Madore, N., Smith, K. L., Graham, C. H., Jen, A., Brady, K., Hall, S., and Morris, R. (1999). Functionally different GPI proteins are organized in different domains on the neuronal surface. EMBO J. 18, 6917-6926.

Maksumova, L., Le, H. T., Muratkhodjaev, F., Davidson, D., Veillette, A., and Pallen, C. J. (2005). Protein tyrosine phosphatase alpha regulates Fyn activity and Cbp/PAG phosphorylation in thymocyte lipid rafts. $J$. Immunol. 175, 7947-7956.

Manes, S., and Viola, A. (2006). Lipid rafts in lymphocyte activation and migration. Mol. Membr. Biol. 23, 59-69.

Marmor, M. D., and Julius, M. (2001). Role for lipid rafts in regulating interleukin-2 receptor signaling. Blood 98, 1489-1497.

Maroun, C. R., and Julius, M. (1994). Distinct roles for CD4 and CD8 as co-receptors in $\mathrm{T}$ cell receptor signalling. Eur. J. Immunol. 24, 959-966.

Marti, F., Garcia, G. G., Lapinski, P. E., MacGregor, J. N., and King, P. D. (2006). Essential role of the T cellspecific adapter protein in the activation of LCK in peripheral $\mathrm{T}$ cells. J. Exp. Med. 203, 281-287.
Mayer, B. J. (1997). Signal transduction: clamping down on Src activity. Curr. Biol. 7, R295-R298.

McNeill, L., Salmond, R. J., Cooper, J. C., Carret, C. K., Cassady-Cain, R. L., Roche-Molina, M., Tandon, P., Holmes, N., and Alexander, D. R. (2007). The differential regulation of Lck kinase phosphorylation sites by CD45 is critical for T cell receptor signaling responses. Immunity 27 , 425-437.

Mendieta, J., and Gago, F. (2004). In silico activation of Src tyrosine kinase reveals the molecular basis for intramolecular autophosphorylation. J. Mol. Graph. Model. 23, 189-198.

Methi, T., Ngai, J., Vang, T., Torgersen, K. M., and Tasken, K. (2007). Hypophosphorylated TCR/CD3zeta signals through a Grb2-SOS1-Ras pathway in Lck knockdown cells. Eur. J. Immunol. 37, 2539-2548.

Meuer, S. C., Schlossman, S. F., and Reinherz, E. L. (1982). Clonal analysis of human cytotoxic T lymphocytes: $\mathrm{T} 4+$ and $\mathrm{T} 8+$ effector $\mathrm{T}$ cells recognize products of different major histocompatibility complex regions. Proc. Natl. Acad. Sci. U.S.A. 79, 4395-4399.

Minguet, S., Swamy, M., Alarcon, B., Luescher, I. F., and Schamel, W. W. (2007). Full activation of the T cell receptor requires both clustering and conformational changes at CD3. Immunity 26, 43-54.

Moarefi, I., Lafevre-Bernt, M., Sicheri, F., Huse, M., Lee, C. H., Kuriyan, J., and Miller, W. T. (1997). Activation of the Src-family tyrosine kinase Hck by $\mathrm{SH} 3$ domain displacement. Nature 385, 650-653.

Munro, S. (2003). Lipid rafts: elusive or illusive? Cell 115, 377-388.

Mustelin, T., Coggeshall, K. M., and Altman, A. (1989). Rapid activation of the T-cell tyrosine protein kinase pp56lck by the CD45 phosphotyrosine phosphatase. Proc. Natl. Acad. Sci. U.S.A. 86, 6302-6306.

Mustelin, T., Pessa-Morikawa, T., Autero, M., Gassmann, M., Andersson, L. C., Gahmberg, C. G., and Burn, P. (1992). Regulation of the p59fyn protein tyrosine kinase by the CD45 phosphotyrosine phosphatase. Eur. J. Immunol. 22, 1173-1178.

Mustelin, T., and Tasken, K. (2003). Positive and negative regulation of T-cell activation through kinases and phosphatases. Biochem. J. 371, 15-27.

Nagafuku, M., Okuyama, K., Onimaru, Y., Suzuki, A., Odagiri, Y.,
Yamashita, T., Iwasaki, K., Fujiwara, M., Takayanagi, M., Ohno, I., and Inokuchi, J.-I. (2012). CD4 and $\mathrm{CD} 8 \mathrm{~T}$ cells require different membrane gangliosides for activation. Proc. Natl. Acad. Sci. U.S.A. 109, E336-E342.

Nam, H. J., Poy, F., Saito, H., and Frederick, C. A. (2005). Structural basis for the function and regulation of the receptor protein tyrosine phosphatase CD45. J. Exp. Med. 201, 441-452.

Nel, A. E. (2002). T-cell activation through the antigen receptor. Part 1: signaling components, signaling pathways, and signal integration at the T-cell antigen receptor synapse. J. Allergy Clin. Immunol. 109, 758-770.

Nika, K., Soldani, C., Salek, M., Paster, W., Gray, A., Etzensperger, R., Fugger, L., Polzella, P., Cerundolo, V., Dushek, O., Hofer, T., Viola, A. and Acuto, O. (2010). Constitutively active Lck kinase in $\mathrm{T}$ cells drives antigen receptor signal transduction. Immunity 32, 766-777.

Nika, K., Tautz, L., Arimura, Y., Vang, T., Williams, S., and Mustelin, T. (2007). A weak Lck tail bite is necessary for Lck function in $\mathrm{T}$ cell antigen receptor signaling. J. Biol. Chem. 282, 36000-36009.

Ostergaard, H. L., Shackelford, D. A., Hurley, T. R., Johnson, P., Hyman, R., Sefton, B. M., and Trowbridge, I. S. (1989). Expression of CD45 alters phosphorylation of the lck-encoded tyrosine protein kinase in murine lymphoma T-cell lines. Proc. Natl. Acad. Sci. U.S.A. 86, 8959-8963.

Otahal, P., Angelisova, P., Hrdinka, M., Brdicka, T., Novak, P., Drbal, K., and Horejsi, V. (2010). A new type of membrane raft-like microdomains and their possible involvement in TCR signaling. J. Immunol. 184 3689-3696.

Otahal, P., Pata, S., Angelisova, P., Horejsi, V., and Brdicka, T. (2011). The effects of membrane compartmentalization of csk on TCR signaling. Biochim. Biophys. Acta 1813, 367-376.

Palacios, E. H., and Weiss, A. (2004). Function of the Src-family kinases, Lck and Fyn, in T-cell development and activation. Oncogene 23 7990-8000.

Paster, W., Paar, C., Eckerstorfer, P., Jakober, A., Drbal, K., Schutz, G. J., Sonnleitner, A., and Stockinger, $\mathrm{H}$. (2009). Genetically encoded Forster resonance energy transfer sensors for the conformation of the Src family kinase Lck. J. Immunol. 182, 2160-2167.
Pizzo, P., Giurisato, E., Bigsten, A., Tassi, M., Tavano, R., Shaw, A., and Viola, A. (2004). Physiological T cell activation starts and propagates in lipid rafts. Immunol. Lett. 91, 3-9.

Quinn, P. J. (2010). A lipid matrix model of membrane raft structure. Prog. Lipid Res. 49, 390-406.

Radeva, G., and Sharom, F. J. (2004). Isolation and characterization of lipid rafts with different properties from RBL-2H3 (rat basophilic leukaemia) cells. Biochem. J. 380, 219-230.

Resh, M. D. (2006). Palmitoylation of ligands, receptors, and intracellular signaling molecules. Sci. STKE 2006, rel4.

Rodgers, W., Farris, D., and Mishra, S. (2005). Merging complexes: properties of membrane raft assembly during lymphocyte signaling. Trends Immunol. 26, 97-103.

Rollet-Labelle, E., Marois, S., Barbeau, K., Malawista, S. E., and Naccache, P. H. (2004). Recruitment of the cross-linked opsonic receptor CD32A (FcgammaRIIA) to high-density detergent-resistant membrane domains in human neutrophils. Biochem. J. 381, 919-928.

Rozdzial, M. M., Pleiman, C. M., Cambier, J. C., and Finkel, T. H. (1998). pp56Lck mediates TCR zetachain binding to the microfilament cytoskeleton. J. Immunol. 161, 5491-5499.

Rudd, M. L., Tua-Smith, A., and Straus, D. B. (2006). Lck SH3 domain function is required for T-cell receptor signals regulating thymocyte development. Mol. Cell. Biol. 26, 7892-7900.

Salmond, R. J., Filby, A., Pirinen, N., Magee, A. I., and Zamoyska, R. (2011). Mislocalization of Lck impairs thymocyte differentiation and can promote development of thymomas. Blood 117, 108-117.

Salmond, R. J., Filby, A., Qureshi, I., Caserta, S., and Zamoyska, R. (2009). T-cell receptor proximal signaling via the Src-family kinases, Lck and Fyn, influences T-cell activation, differentiation, and tolerance. Immunol. Rev. 228, 9-22.

Samelson, L. E., Phillips, A. F., Luong, E. T., and Klausner, R. D. (1990). Association of the fyn protein-tyrosine kinase with the T-cell antigen receptor. Proc. Natl. Acad. Sci. U.S.A. 87, 4358-4362.

Schoenborn, J. R., Tan, Y. X., Zhang, C., Shokat, K. M., and Weiss, A. (2011). Feedback circuits monitor and adjust basal Lck-dependent events in $\mathrm{T}$ cell receptor signaling. Sci. Signal. 4, ra59. 
Schuck, S., Honsho, M., Ekroos, K., Shevchenko, A., and Simons, K. (2003). Resistance of cell membranes to different detergents. Proc. Natl. Acad. Sci. U.S.A. 100, 5795-5800.

Seavitt, J. R., White, L. S., Murphy, K. M., Loh, D. Y., Perlmutter, R. M., and Thomas, M. L. (1999). Expression of the p56(Lck) Y505F mutation in CD45-deficient mice rescues thymocyte development. Mol. Cell. Biol. 19, 4200-4208.

Sharma, P., Varma, R., Sarasij, R. C., Ira, Gousset, K., Krishnamoorthy, G., Rao, M., and Mayor, S. (2004). Nanoscale organization of multiple GPI-anchored proteins in living cell membranes. Cell 116, 577-589.

Shaw, A. S. (2006). Lipid rafts: now you see them, now you don't. Nat. Immunol. 7, 1139-1142.

Sherman, E., Barr, V., Manley, S., Patterson, G., Balagopalan, L., Akpan, I., Regan, C. K., Merrill, R. K., Sommers, C. L., Lippincott-Schwartz, J., and Samelson, L. E. (2011). Functional nanoscale organization of signaling molecules downstream of the $\mathrm{T}$ cell antigen receptor. Immunity 35 , 705-720.

Sicheri, F., Moarefi, I., and Kuriyan, J. (1997). Crystal structure of the Src family tyrosine kinase Hck. Nature 385, 602-609.

Sigalov, A. B. (2010). The SCHOOL of nature: I. Transmembrane signaling. Self Nonself 1, 4-39.

Simons, K., and Ikonen, E. (1997). Functional rafts in cell membranes. Nature 387, 569-572.

Simons, K., and Sampaio, J. L. (2011). Membrane organization and lipid rafts. Cold Spring Harb. Perspect. Biol. 3, a004697.

Simons, K., and Toomre, D. (2000). Lipid rafts and signal transduction. Nat. Rev. Mol. Cell Biol. 1, 31-39.

Smida, M., Posevitz-Fejfar, A., Horejsi, V., Schraven, B., and Lindquist, J. A. (2007). A novel negative regulatory function of the phosphoprotein associated with glycosphingolipidenriched microdomains: blocking Ras activation. Blood 110, 596-615.

Smith-Garvin, J. E., Koretzky, G. A., and Jordan, M. S. (2009). T cell activation. Annu. Rev. Immunol. 27, 591-619.
Stone, J. D., Conroy, L. A., Byth, K. F., Hederer, R. A., Howlett, S., Takemoto, Y., Holmes, N., and Alexander, D. R. (1997). Aberrant TCR-mediated signaling in CD45null thymocytes involves dysfunctional regulation of Lck, Fyn, TCRzeta, and ZAP-70. J. Immunol. 158, 5773-5782.

Straus, D. B., and Weiss, A. (1992). Genetic evidence for the involvement of the lck tyrosine kinase in signal transduction through the $\mathrm{T}$ cell antigen receptor. Cell 70, 585-593.

Sugie, K., Jeon, M. S., and Grey, H. M. (2004). Activation of naive CD4 $\mathrm{T}$ cells by anti-CD3 reveals an important role for Fyn in Lckmediated signaling. Proc. Natl. Acad. Sci. U.S.A. 101, 14859-14864.

Tang, Q., Subudhi, S. K., Henriksen, K. J., Long, C. G., Vives, F., and Bluestone, J. A. (2002). The Src family kinase Fyn mediates signals induced by TCR antagonists. J. Immunol. 168, 4480-4487.

Tavano, R., Contento, R. L., Baranda, S. J., Soligo, M., Tuosto, L., Manes, S., and Viola, A. (2006). CD28 interaction with filamin-A controls lipid raft accumulation at the T-cell immunological synapse. Nat. Cell Biol. 8, 1270-1276.

Tavano, R., Gri, G., Molon, B., Marinari, B., Rudd, C. E., Tuosto, L., and Viola, A. (2004). CD28 and lipid rafts coordinate recruitment of Lck to the immunological synapse of human T lymphocytes. J. Immunol. 173, 5392-5397.

Tedoldi, S., Paterson, J. C., Hansmann, M. L., Natkunam, Y., Rudiger, T., Angelisova, P., Du, M. Q., Roberton, H., Roncador, G., Sanchez, L., Pozzobon, M., Masir, N., Barry, R., Pileri, S., Mason, D. Y., Marafioti, T., and Horejsi, V. (2006). Transmembrane adaptor molecules: a new category of lymphoid-cell markers. Blood 107, 213-221.

Trowbridge, I. S., and Thomas, $\mathrm{M}$. L. (1994). CD45: an emerging role as a protein tyrosine phosphatase required for lymphocyte activation and development. Annu. Rev. Immunol. 12, 85-116.

Vacaresse, N., Moller, B., Danielsen, E. M., Okada, M., and Sap, J. (2008). Activation of c-Src and Fyn kinases by protein-tyrosine phosphatase RPTPalpha is substratespecific and compatible with lipid raft localization. J. Biol. Chem. 283, 35815-35824.

Van Laethem, F., Sarafova, S. D., Park, J. H., Tai, X., Pobezinsky, L., Guinter, T. I., Adoro, S., Adams, A., Sharrow, S. O., Feigenbaum, L., and Singer, A. (2007). Deletion of CD4 and CD8 coreceptors permits generation of alphabetaT cells that recognize antigens independently of the MHC. Immunity 27, 735-750.

van Oers, N. S., Killeen, N., and Weiss, A. (1996). Lck regulates the tyrosine phosphorylation of the $\mathrm{T}$ cell receptor subunits and ZAP-70 in murine thymocytes. J. Exp. Med. 183 , 1053-1062.

Veillette, A., Latour, S., and Davidson, D. (2002). Negative regulation of immunoreceptor signaling. Annu. Rev. Immunol. 20, 669-707.

Viola, A., and Gupta, N. (2007). Tether and trap: regulation of membraneraft dynamics by actin-binding proteins. Nat. Rev. Immunol. 7, 889-896.

Werlen, G., and Palmer, E. (2002). The T-cell receptor signalosome: a dynamic structure with expanding complexity. Curr. Opin. Immunol. 14, 299-305.

Williamson, D. J., Owen, D. M., Rossy, J., Magenau, A., Wehrmann, M., Gooding, J. J., and Gaus, K. (2011). Preexisting clusters of the adaptor Lat do not participate in early $\mathrm{T}$ cell signaling events. Nat. Immunol. 12, 655-662.

Wucherpfennig, K. W., Gagnon, E., Call, M. J., Huseby, E. S., and Call, M. E. (2010). Structural biology of the T-cell receptor: insights into receptor assembly, ligand recognition, and initiation of signaling. Cold Spring Harb. Perspect. Biol. 2, a005140.

$\mathrm{Xu}$, C., Gagnon, E., Call, M. E. Schnell, J. R., Schwieters, C. D., Carman, C. V., Chou, J. J., and Wucherpfennig, K. W. (2008). Regulation of $\mathrm{T}$ cell receptor activation by dynamic membrane binding of the CD3epsilon cytoplasmic tyrosinebased motif. Cell 135, 702-713.

$\mathrm{Xu}, \mathrm{W}$., Harrison, S. C., and Eck, M. J. (1997). Three-dimensional structure of the tyrosine kinase c-Src. Nature 385, 595-602.
Yamaguchi, H., and Hendrickson, W. A. (1996). Structural basis for activation of human lymphocyte kinase Lck upon tyrosine phosphorylation. Nature 384, 484-489.

Yasuda, T., Bundo, K., Hino, A., Honda, K., Inoue, A., Shirakata, M., Osawa M., Tamura, T., Nariuchi, H., Oda, H., Yamamoto, T., and Yamanashi, Y. (2007). Dok-1 and Dok-2 are negative regulators of $\mathrm{T}$ cell receptor signaling. Int. Immunol. 19, 487-495.

Zamoyska, R., Basson, A., Filby, A., Legname, G., Lovatt, M., and Seddon, B. (2003). The influence of the srcfamily kinases, Lck and Fyn, on T cell differentiation, survival and activation. Immunol. Rev. 191, 107-118.

Zeyda, M., and Stulnig, T. M. (2006). Lipid Rafts \& Co.: an integrated model of membrane organization in T cell activation. Prog. Lipid Res. 45, 187-202.

Zhang, W., Sommers, C. L., Burshtyn, D. N., Stebbins, C. C., Dejarnette, J. B., Trible, R. P., Grinberg, A., Tsay, H. C., Jacobs, H. M., Kessler, C. M., Long, E. O., Love, P. E., and Samelson, L. E. (1999). Essential role of LAT in $\mathrm{T}$ cell development. Immunity 10 , 323-332.

Conflict of Interest Statement: The authors declare that the research was conducted in the absence of any commercial or financial relationships that could be construed as a potential conflict of interest.

Received: 01 February 2012; accepted: 25 May 2012; published online: 12 June 2012.

Citation: Filipp D, Ballek $O$ and Manning J (2012) Lck, membrane microdomains, and TCR triggering machinery: defining the new rules of engagement. Front. Immun. 3:155. doi: 10.3389/fimmu.2012.00155

This article was submitted to Frontiers in $T$ Cell Biology, a specialty of Frontiers in Immunology.

Copyright (c) 2012 Filipp, Ballek and Manning. This is an open-access article distributed under the terms of the Creative Commons Attribution Non Commercial License, which permits noncommercial use, distribution, and reproduction in other forums, provided the original authors and source are credited. 